1 Sensitivity of the Distribution of Thunderstorms to

2 Sea Surface Temperatures in Four Australian East

3

4

5

6

7

8

9

10

11

12

13

14

15

16

17

18

19

20

21 Corresponding author address: Kevin Walsh, School of Earth Sciences, University of Melbourne 3010,

22 Victoria, Australia.

23 E-mail: kevin.walsh@unimelb.edu.au

24 Tel: $61(0) 383446523$

Christopher R. S. Chambers

School of Earth Sciences, University of Melbourne, Parkville, Australia

Gary B. Brassington

Centre for Australian Weather and Climate Research, Bureau of Meteorology, Sydney,

Australia

Kevin Walsh

School of Earth Sciences, University of Melbourne, Parkville, Australia

Ian Simmonds

School of Earth Sciences, University of Melbourne, Parkville, Australia

\title{
Coast Lows
}




\section{Abstract}

26 The relationship between the sea surface temperature (SST) distribution and the locations of

27 thunderstorms during four Australian east coast lows is investigated using both lightning

28 observations and numerical simulation results. The focus is placed on investigating changes in convective instability caused by the introduction of complex, high-resolution ocean eddy and frontal structures present in Bluelink SST datasets. Global Position and Tracking System lightning data are overlaid on maps of SST to investigate whether a thunderstorm-SST relationship is discernible. Weather Research and Forecast model simulations are used to establish what atmospheric changes contribute to the observed distributions of thunderstorms.

34 Maximum convective available potential energy (MCAPE) analysis shows a distinct relationship to the SST distribution. In particular areas of elevated MCAPE are related to regions of warmer SST with horizontal advection often displacing increased MCAPE downwind of the warmer SST. At short timescales of 3 to 6 hours, the differences in MCAPE become larger and more localized and show a strong correlation with the observed lightning. This suggests that at times the thunderstorms are directly related to the complex structures in the detailed SST dataset. For the damaging Pasha Bulker case the plume of thunderstorms associated with the coastal damage occurs downwind of the region of enhanced MCAPE on

42 the southern flank of the warm eddy. Based on these results it is concluded that the particular

43 features of the warm eddy enhanced the thunderstorm potential over the coastal region during

44 this event and helped in localising the area of greatest impact for thunderstorm related intense rainfall. 


\section{Introduction}

47 Australian east coast lows (ECLs) or east coast cyclones (Bridgman 1985, Holland et al. 1987, McInnes et al. 1992, Qi et al. 2006, Browning and Goodwin 2013, Dowdy et al. 2013a, b, Pepler et al. 2014) are subtropical low pressure weather systems that tend to develop rapidly over the oceanic region where the warm East Australian Current (EAC) flows southward off the east coast of Australia. ECLs can have characteristics of both tropical and extratropical cyclones (Evans and Guishard 2009) and are thought to develop through both baroclinic instability and diabatic heating related instabilities (Hart 2003).

ECLs have historically been responsible for major flooding events, damage to coastal infrastructure, and the wrecking and beaching of multiple ships including the Norwegian bulk carrier the Sygna in May 1974 (Bridgeman 1986) and the bulk carrier Pasha Bulker in June 2007 (Mills et al. 2010). ECLs are notoriously difficult to forecast, in part because of their tendency to rapidly intensify overnight. In addition, features within these storms, such as thunderstorm bands, can localize the impact, increasing further the complications in producing an accurate forecast. Ocean eddies in the EAC produce a complicated sea surface temperature (SST) distribution that affects the rainfall distribution and coastal impacts from ECLs (Chambers et al. 2014). This work expands on Chambers et al. by investigating whether the distribution of thunderstorms within three additional ECLs are related to the SST distribution.

On the large scale, ECLs typically develop under consistent upper and lower-level atmospheric patterns. The lower-atmospheric pattern is a low or trough in the subtropical easterly flow known as an "easterly dip" (Fandry and Leslie 1984) that has a ridge on its poleward side. ECLs can develop when an easterly dip develops under, or to the east of, a mid-tropospheric cold-core cyclone or trough in the upper tropospheric westerlies. The cold pools and associated cut-off cyclones present at the beginning of each of the four ECLs in 
this study are shown in Figure 1. As the pool of cold air moves eastward, it passes from relatively dry continental Australia to the warm moist air mass present over the warm waters of the EAC. The presence of cold air above warm moist low level air leads to an increase in vertical buoyant instability making the troposphere more favourable for deep convection. The EAC is a western boundary current of the South Pacific sub-tropical gyre that propagates poleward along the east coast of Australia (Figure 2). The EAC transports warm tropical water from the Coral Sea poleward to the Tasman Sea and has a much greater eddy kinetic energy than other western boundary currents (Hamon, 1965; Stammer, 1997; Brassington et al., 2011). Consequently, anticyclonic warm eddies of the order of $250 \mathrm{~km}$ diameter are shed from the current near $32^{\circ} \mathrm{S}$. The warm eddies can have a mixed layer depth exceeding $300 \mathrm{~m}$ in their core (Andrews and Scully-Power 1976) and their rotation and deep vertical structure resists cooling of the eddy interior. As warm eddies move southward they enter a progressively cooler ocean environment leading to the development of localised regions of strong SST gradients.

SST gradients have been found to impact the overlying atmosphere in a number of ways that could influence thunderstorm development. In regions of large SST gradients which occur near meandering ocean currents such as the EAC, previous research has shown a strong positive correlation between SST and surface wind speed perturbations at spatial scales of between 100 and $1000 \mathrm{~km}$ (see the review by Small et al. 2008). Radar observations of a persistent area of rain over the Gulf Stream led Hobbs (1987) to introduce the concept of a 'Gulf Stream rainband'. Warner et al. (1990) found that sharp SST gradients in the vicinity of the Gulf Stream triggered convergence in the lower troposphere. The Gulf Stream rainband has been associated with rapidly developing

94 thunderstorms (Trunk and Bosart, 1990, Christian et al., 2003, Li et al., 2004) and convective 
precipitation has been found to be sensitive to SST gradients along the flanks of the Gulf Stream (Kuwano-Yoshida et al. 2010).

Recent studies have confirmed that modifications of lower-tropospheric flow by mesoscale SST gradients can translate upward and can trigger or enhance atmospheric convection (Minobe et al. 2008; Vianna et al. 2010; Xu et al. 2011; Li and Carbone 2012). Miyama et al. (2012) found that a convective rainband over the Kuroshio Current was successfully simulated only when a high resolution SST dataset was prescribed. Modelling experiments incorporating smoothed SST fronts in the East China Sea have been completed by $\mathrm{Xu}$ et al. (2011) and Tanimoto et al. (2011) and have demonstrated the importance of incorporating detailed SSTs to generate accurate weather simulations. By comparing smoothed SST with high-resolution SST simulations of a Baiu rain event over the Kuroshio, Sasaki et al. (2012) demonstrated that the convective available potential energy (CAPE) difference between the simulations was positively correlated with the SST difference. The increased CAPE was attributed to increased equivalent potential temperature in the boundary layer from enhanced surface fluxes off the warmer ocean surface.

While previous research has established these important results concerning the role of SST gradients on the atmosphere, the dependence of the response on conditions in the atmosphere has not been extensively studied. The vertical mixing of momentum will depend on the vertical wind shear and buoyancy in the lower troposphere, as well as on storm features such as regions of convergence and convection. An ECL is often associated with unstable conditions and complicated vertical wind shear distributions because of the typical presence of a cold-core mid-level cyclone propagating across the warm EAC. It is unknown how this will affect the SST-atmospheric response. In addition, previous research has been primarily concerned with timescales of days or longer but in an ECL the significant damaging weather usually occurs on timescales of hours. Therefore, for the purpose of forecasting, it is 
120 of paramount interest to determine how these SST gradient responses develop on shorter

121 timescales during these damaging storm events to determine if they play a significant role. This study compares observed lightning with simulated CAPE, two factors that have

123 been found to be related in past studies. Larger CAPE has been associated with the potential

124 for more vigorous convection which promotes more lightning (Williams et al. 1992; Rutledge

125 et al. 1992). Williams et al. found that during transition from a break period to the monsoon over Darwin the lightning yield decreased by more than an order of magnitude for a halving of CAPE. This corresponds to a decrease in CAPE of the order $1000 \mathrm{Jkg}^{-1}$ which was in turn found to be equivalent to a decrease in surface wet-bulb temperature of about $1^{\circ} \mathrm{C}$. Buechler et al. (1994) noted a similar sensitivity for mid-latitude thunderstorms. Additionally, several

130 studies have found correlations between lightning and precipitation rate (Alexander et al 1999; Chang et al. 2001; Pessi and Businger 2009). While thunderstorms occurring in an environment with larger CAPE would be expected to have more lightning, there are other critical factors that will influence the occurrence and intensity of a lightning producing

134 thunderstorm, such as adequate moisture through the troposphere, vertical wind shear, and 135 some form of trigger. The rate of lightning strikes has been found to be positively correlated with the strength of convection (Orville and Vonnegut 1974; Orville et al. 1983; Williams et al. 1992). In the case of tropical cyclones (TCs) there have been a number of investigations into the 139 potential relationship between intensification and the distribution and rate of lightning strikes.

140 Black and Hallet (1999) concluded that generally weak vertical velocities within the eyewall, 141 combined with few supercooled water droplets, limits charge separation and consequently 142 leads to sparse lightning in TC cores. A greater likelihood of eyewall lightning in strong TCs 143 was found by Cecil and Zipser (1999) and greater inner-core lightning during intensification

144 by Squires and Businger (2008) and Abarca and Corbosiero (2011). DeMaria et al. (2012) 
145 also found intensifying TCs to have greater lightning density than weakening ones, however

146 the largest lightning densities were found in sheared storms that do not intensify much. They

147 also concluded that inner-core lightning outbreaks can be a signal that an intensification

148 period is coming to an end.

149 With these considerations in mind, we focus on ECLs, using the lightning data to

150 compare with model data to investigate whether the distribution of the thunderstorms is

151 sensitive to the SST initialisation. Lightning data provides a useful source of information for

152 the location of thunderstorms particularly in remote ocean areas that are partially or totally

153 beyond the range of weather radar. The paper will look at the sensitivity of atmospheric

154 instability to changing the SST from a coarse dataset to an ocean eddy resolving dataset. It

155 will investigate this sensitivity at 48-hour, 12-hour, and 3-hour timescales and compare the 156 sensitivity with the observed distribution of lightning.

157 The investigation is presented as follows. Section 2 describes the four ECL case studies 158 and methodology, section 3 presents the simulation and lightning data analysis results, with 159 the discussion in section 4 and the overall conclusions in section 5.

\section{Case studies and method}

161 Four ECL case studies have been chosen for this study, two in 2007 and two in 2012. A

162 justification for analysing four contrasting examples is to get a more comprehensive

163 understanding of the relationships between the SST, convection and lightning. The first case 164 (JUN07a) covers the period from 1200 UTC 6 to 0000 UTC 9 June 2007. This event caused over $\$ 1.5$ billion in damages and led to the beaching of the bulk carrier, the Pasha Bulker at 2315 UTC 7 June (0915 EST 8 June) on Nobbys Beach in Newcastle, New South Wales.

167 The low had a wide and persistent band of strong onshore winds associated with a strong

168 pressure gradient on its southern side (Figure 3a) that was responsible for the generation of 
very rough seas, with the Sydney wave-rider buoy $\left(33.8^{\circ} \mathrm{S} 151.4^{\circ} \mathrm{E}\right)$ recording $14.1 \mathrm{~m}$ maximum wave heights. From 0200 UTC (1200 EST) to 1600 UTC 8 June (0200 EST 9

171 June), a long lasting, slowly southward propagating, east-west oriented thunderstorm

172 rainband moved onshore in the Newcastle area, leading to very high and localized rainfall.

173 Within this rainband, an intense mesoscale low pressure developed offshore and moved 174 onshore at 1500 UTC 8 June (0100 EST 9 June). In the ocean, a large warm eddy was present centred at $33^{\circ} \mathrm{S}, 155^{\circ} \mathrm{E}$ as shown in Figure 4a. The sensitivity of rainfall to the introduction of eddy-resolving SSTs has been investigated in Chambers et al. (2014) and they concluded that the presence of a large warm eddy led to a marked enhancement in rainfall along its southern flank. The more detailed SST specifications also produced a better agreement with coastal observations.

The second case (JUN07b) occurred several days later in a similar location. The almost stationary low developed near the coast between 1200 UTC 15 June and 1200 UTC 16 June before moving offshore. The minimum sea level pressure reached for this system was 1003 $\mathrm{hPa}$ at $0600 \mathrm{UTC} 17$ June, as shown in Figure 3b. Impacts were less than in the JUN07a case although snow over higher ground did lead to the accumulation of $30 \mathrm{~cm}$ south of Bungendore $\left(35.25^{\circ} \mathrm{S}, 149.45^{\circ} \mathrm{E}\right.$, location marked on Figure $\left.4 \mathrm{a}\right)$. It has been chosen to compare with the first case because the position of a warm ocean eddy had not moved a large distance in the period between the two storms, as can be seen by comparing Figure $4 a$ and $b$. In the APR12 case, a low pressure system developed rapidly off the south-eastern coast of 189 Australia from 24 to 25 April, 2012. The Australian Bureau of Meteorology (BOM) analysis 190 shows a pressure drop of $6 \mathrm{hPa}$ in 6 hours from 0000 UTC 25 April 2012 to $995 \mathrm{hPa}$ (Figure 3c). A MODIS pass at 0325 UTC 15 April (not shown) showed a clearly defined cyclone with multiple deep convective rainbands. Despite the impressive nature of this ECL, there 
193 were no significant noted impacts, mainly due to a north-eastward track that took it away

194 from the coast.

The JUN12 case was another ECL that developed near the southeast corner of

196 Australia on 4 June 2012. This time the low moved towards the coast before moving rapidly

197 north along the coast. According to the BOM sea level pressure analyses the central pressure

198 dropped $12 \mathrm{hPa}$ between 0000 and $0600 \mathrm{UTC} 4$ June to $986 \mathrm{hPa}$ (Figure 3d). This ECL

199 brought strong winds and heavy rain to southeast New South Wales. The highest wind gust

200 recorded was $128 \mathrm{~km} \mathrm{~h}^{-1}$ at Wattamolla at 3:30 pm 5 June, while 13.8 metre waves were

201 recorded at Sydney.

\section{Model setup}

The four ECLs described above are simulated using the Weather Research and

204 Forecasting (WRF) Model version 3.3.1 (Skamarock et al. 2005). Two domains on a Lambert conformal grid, with resolutions of 15 and $3 \mathrm{~km}$, are used for the simulations, as shown in

Figure 2, with different domain locations for the 2007 and 2012 cases. The central grid point is shifted so that the inner domain lies over the region of ECL formation. The outer domain is 221 by 171 grid points ( $3315 \mathrm{~km}$ by $2565 \mathrm{~km}$ ) and the inner domain is 301 by 261 grid points (903 km by $783 \mathrm{~km})$. Fifty five levels are used in the vertical with a model top at $30 \mathrm{hPa}$. One degree National Centers for Environmental Prediction (NCEP) Final (FNL) Analysis data

211 (Global Climate and Weather Modeling Branch 2003) is used to initialize the atmosphere in 212 the model.

214 (water vapor, cloud water, rain, snow, graupel, and cloud ice) is used. The Betts-Miller-Janjic

215 (Betts and Miller 1986; Janjic 1994) cumulus scheme is used only on the outer domain, with

216 the inner domain calculating the cumulus processes explicitly. Explicit depiction of

217 convection at 3-km resolution is thought to be sufficient to resolve mesoscale convective 
218 features (Weisman et al. 1997). Other physics schemes used are the Yonsei University

219 planetary boundary layer parameterization, the Monin-Obukhov surface layer scheme (Hong et al. 2006), the Dudhia (1989) short wave radiation scheme, and the Rapid Radiative Transfer Model for long wave radiation with six molecular species (Mlawer et al. 1997). Two 60-hour simulations are conducted for each of the four ECLs that are identical except for the SST data used as input. The first 12 hours of the simulations are considered a "spin-up" period during which the results are not analysed. The simulation names, integration periods, and SST configurations used are summarised in Table 1. For all cases the SST evolves on a 6-hourly basis to match the atmospheric data input period. The first of the SST configurations (Skin) is the 1 degree resolution skin temperature from the NCEP FNL data that are derived from the Global Data Assimilation System (GDAS). As the middle column of Figure 4 shows, this dataset does not resolve any eddy variability in the EAC on domain 2 . The second configuration is for the 2007 cases and uses Bluelink ReANalysis (BRAN, Schiller et al. 2008) SST. BRAN uses SST data from an eddy-resolving ocean model simulation using the Modular Ocean Model (MOM, Griffies et al. 2004) which is constrained through the data assimilation of altimetry, SST and in situ profiles using the Bluelink Ocean Data Assimilation System (BODAS, Oke et al. 2008). The BRAN output data is dailyaveraged and is here time-interpolated to be 6 hourly to fit with the atmospheric initial conditions. In an Australian-centred region $\left(75^{\circ} \mathrm{S}-16^{\circ} \mathrm{N}, 90^{\circ} \mathrm{E}-180^{\circ} \mathrm{E}\right)$ the BRAN data has a resolution of 0.1 degrees, and the WRF model domains used here are within this region.

238 The BRAN data contains complex SST structures in the EAC with mesoscale filaments and 239 eddies present, as can be seen in Figure $4 \mathrm{a}$ and $\mathrm{d}$.

241 (OceanMAPS) version 2 (Brassington et al. 2012) SST is used. As with BRAN, OceanMAPS 242 uses a global ocean model based on the Modular Ocean Model version 4 (MOM4) with 
assimilated BODAS observations and has a spatial resolution of 0.1 degrees. Since both the

244 BRAN and the OceanMAPS both utilize MOM, they produce qualitatively similar SST

245 structures in the EAC with mesoscale filaments and eddies present, as can be seen in the left

246 column of Figure 4.

\section{Lightning and MCAPE analysis}

In addition to the WRF simulations, lightning data from the commercial provider

Global Positioning and Tracking System Pty. Ltd. (GPATS 2013) is used to analyse the

distribution of thunderstorms in relation to the SST. GPATS data requires the arrival time of a lightning discharge to be recorded at three or more radio receivers (Cummins and Murphy 2009). This allows for the detection of return strokes and the ability to distinguish between cloud-to-cloud and cloud-to-ground lightning. The analysis conducted here concentrates on lightning strike locations over given time periods that are compared with the model results over the same periods.

The maximum convective available potential energy (MCAPE) is used to investigate the sensitivity of tropospheric vertical instability to the SST distribution. MCAPE is calculated as the CAPE at the level of greatest instability (Colman 1990). Specifically, in the post-processing phase of WRF the MCAPE is calculated as the CAPE from the air parcel with the maximum equivalent potential temperature in the lowest $3 \mathrm{~km}$. CAPE (Moncrieff and Miller 1976) is calculated by integrating the local buoyancy of a parcel from the level of free convection to the equilibrium level. CAPE is a measure of instability through the depth of the troposphere, is related to updraft strength, and is used to indicate thunderstorm potential. MCAPE has been chosen rather than CAPE calculated using a parcel from the surface, to compare with the observed lightning strikes, because the thunderstorms of interest here could be surface based or elevated. Over the strong SST gradients present during these cases the flow of warm moist air over cooler SSTs may lead to the warm air overrunning the 
cooler near-surface air. In these situations it is more insightful to analyse the MCAPE rather than surface based CAPE because the most unstable layer that triggers the thunderstorms may not be at the surface.

\section{Results}

272 For the four ECL case studies the first 12 hours of the 60-hour simulations are not analysed as this is considered a spin up period, which leaves the remaining 48 hours as the analysis period. In the following analysis references to 'detailed run' refer to the BRAN or OceanMAPS SST initialised simulations for the 2007 and 2012 cases respectively. Three different timescales are investigated. The first is the 48-hour average that provides a less noisy signal with which we can identify associations with SST more clearly. Secondly, 12hour averages provide a view during the different phases of the ECLs' development. Thirdly, for specific lightning active periods, 3-hourly averages allow a view on a timescale more

280 relevant to the thunderstorm lifecycles.

\section{2-day average structures}

The 48-hour average simulated MCAPE for each of the cases is plotted in Figure 5 to provide a general overview of the convective energy situation. The broad distribution of average MCAPE shows some similarities between the detailed and skin SST runs while local differences can be seen. This suggests that the changes to the SST do not lead to large changes in the broad synoptic-scale features of the storms so, for example, the areas of lowlevel warm advection remain in similar locations and are generally associated with the high MCAPE regions in Figure 5. Also of note is the lack of MCAPE over the land interior with significant MCAPE only occurring over the coastal regions. During the 48-hour period over which these averages are taken there are considerable changes to the MCAPE due to the approach and passage of the cold-core upper-level trough. 

visualization of relationships with MCAPE. Comparing Figure 5a and $b$ it is apparent that the warm SSTs over the central warm eddy (centred at $32.5^{\circ} \mathrm{S}, 154.5^{\circ} \mathrm{E}$ ) in JUN07a_BN are responsible for higher 48-hour averaged MCAPE than in JUN07a_skin. Also lower MCAPE in JUN07a_BN located east of the warm eddy over the tongue of cold water near $32^{\circ} \mathrm{S}, 157^{\circ}$

297 E, is largely absent from JUN07a_skin. Of potential significance for the coastal impacts of 298 this case is the MCAPE local maximum of $350 \mathrm{~J} \mathrm{~kg}^{-1}$ seen offshore at $33^{\circ} \mathrm{S}, 153^{\circ} \mathrm{E}$ that is not present in JUN07a_skin. The JUN07a_BN average 10-metre wind vectors shown in Figure 5a indicate that downwind of this maximum is a large negative temperature gradient associated with cooler water nearer the coast near $33^{\circ} \mathrm{S}, 152.5^{\circ} \mathrm{E}$.

For the JUN07b cases (Figure 5c and d) the 48-hour average MCAPE is greater than the JUN07a cases along a broad band oriented southwest to northeast across domain 2. This band of MCAPE is narrower in JUN07b_BN with a sharper southward reduction located near $34^{\circ} \mathrm{S}, 154^{\circ} \mathrm{E}$. This occurs in a region of strong SST gradients (cooling southward) along the southern edge of the central warm eddy. Around $31^{\circ} \mathrm{S}, 157.5^{\circ} \mathrm{E}$ is a region that has the highest averaged MCAPE in JUN07b_BN of either of the JUN07b cases, locally in excess of $600 \mathrm{~J} \mathrm{~kg}^{-1}$.

For APR12 (Figure 5e and $\mathrm{f}$ ) there is a broad band of high MCAPE in both cases east of $152^{\circ}$ E. APR12_skin has substantially larger, in both magnitude and areal extent, MCAPE

311 within the band, particularly in the southern portions. APR12_skin fails to resolve multiple 312 regions of SST gradients within the southern region that are present in APR12_OM. For the

313 JUN12 cases (Figure 5g and $\mathrm{h}$ ) there are less prominent MCAPE changes with broadly 314 similar distributions in both JUN12_OM and JUN12_skin. Of note is an area of higher 315 MCAPE in JUN12_OM near $35^{\circ} \mathrm{S}, 156.5^{\circ} \mathrm{E}$ and lower MCAPE in the region near $37.5^{\circ} \mathrm{S}$, $316152^{\circ} \mathrm{E}$ associated with a greater east-west SST drop in JUN12_OM. 

between the detailed SST and the skin SST runs are plotted for each case in Figure 6. In this

319 figure positive MCAPE differences are coloured in blue and green because of the association 320 of high MCAPE with heavy rain. The two 2007 cases (Figure 6a and b) show that average 321 MCAPE was greater by between $50-100 \mathrm{~J} \mathrm{~kg}^{-1}$ over the same prominent central warm eddy 322 that persisted through the period covered by the two cases. There is also reduced MCAPE associated with cooler waters in the detailed cases, with the largest reductions east of the central warm eddy in both cases. In JUN07b MCAPE is reduced more than in JUN07a to the east and south of the warm eddy. This corresponds to a larger (cooler) difference in SST in JUN07b in these regions (Figure 4f). positive MCAPE differences occur on the downwind (southern) side of the central warm eddy, with maxima at $33.5^{\circ} \mathrm{S}, 155.5^{\circ} \mathrm{E}$ and at $33^{\circ} \mathrm{S}, 153^{\circ} \mathrm{E}$, the latter location associated with the offshore MCAPE max highlighted in the analysis of Figure 5a. The largest negative MCAPE differences occur on the downwind side of the colder SSTs east of the warm eddy, for example at $33^{\circ} \mathrm{S}, 157^{\circ} \mathrm{E}$. In the persistent and strong east-southeasterly flow south of the warm eddy the relationship is less clear, probably due to the strong advection of low-level heat and moisture. Where heat and moisture is advected, regions of elevated MCAPE can be correspondingly displaced. An example of the displacement is found in a region of positive MCAPE difference near $35^{\circ} \mathrm{S}, 155.5^{\circ} \mathrm{E}$ that is associated with the upstream warm eddy at $36^{\circ} \mathrm{S}, 156.5^{\circ} \mathrm{E}$. While there are considerable changes to the storm over this 48 -hour period, the quasi-stationary nature of the low pressure caused flow to be persistently eastsoutheasterly across this region, lending confidence to this proposed advection relationship. The JUN07b case provides an interesting comparison with JUN07a because the SST

341 distribution is similar to JUN07a. The average 10-metre wind flow is different to JUN07a and 
the MCAPE difference distribution appears correspondingly shifted in Figure 6b. The shift occurs because the locations of greatest low-level heat and moisture advection off the eddy are changed because of the different pattern of wind flow. In particular the largest positive MCAPE differences now occur over the northwest section of the central warm eddy around $32^{\circ} \mathrm{S}, 155^{\circ} \mathrm{E}$. The wind vectors indicate that the flow turns from east-south-easterly to southerly over the warm eddy which means that the region of largest positive MCAPE difference over the eddy is again over the downwind side. The largest negative MCAPE differences can also be seen to occur on the downstream side of the regions of cooler SSTs. The 48-hour CAPE differences associated with the 2012 cases (Figure 6c and d) also exhibit positive/negative relationships with positive/negative SST difference. The

APR12_OM case contained a warm current jet that spread southward from the southeast corner of Australia into a warm eddy near $40^{\circ} \mathrm{S}, 151^{\circ} \mathrm{E}$ as shown in Figure $4 \mathrm{~g}$. Cooler water located east of this feature leads to an east-west dipole in SST that is not present in the APR12_skin case. Figure 6c shows that these SST features lead to a corresponding east-west dipole in the MCAPE differences in the region south of $35^{\circ} \mathrm{S}$ and between $150^{\circ}$ and $156^{\circ} \mathrm{E}$ and strongest near $40^{\circ} \mathrm{S}, 153^{\circ} \mathrm{E}$. The negative MCAPE differences dominate because of the larger region of negative SST difference. As with the 2007 cases, 48-hour average winds in APR12_OM show that the greatest negative MCAPE differences occur downwind of the greatest negative SST differences throughout the central region where average winds are 10 $\mathrm{m} \mathrm{s}^{-1}$ or more. South of $39^{\circ} \mathrm{S}$ and east of $153^{\circ} \mathrm{E}$, where the average winds are lighter, there is

362 less downwind displacement of MCAPE consistent with less average lower tropospheric heat and moisture advection in this region. The region of maximum positive MCAPE difference at $40.5^{\circ} \mathrm{S}, 153^{\circ} \mathrm{E}$ is less easy to explain. It lies on the eastern edge of the warm eddy in southerly flow. Potentially, moisture convergence in APR12_OM simulations associated with the SST gradients in this region (Figure 4g) during the intensification phase of the ECL that 
occurred over this area played a role. Whatever the process, it will be shown later that this region was associated with concentrated thunderstorm activity. difference and SST differences, with MCAPE differences on the downwind sides of SST differences particularly evident in the strong 48 -hour average flow south of $38^{\circ} \mathrm{S}$. The largest positive MCAPE differences of over $140 \mathrm{~J} \mathrm{~kg}^{-1}$ occur in south-westerly flow over a strong SST gradient region in JUN12_OM on the southeast edge of a warm eddy near $35.5^{\circ} \mathrm{S}, 153^{\circ}$

E. There are similar characteristics in the area of largest positive MCAPE difference in APR12 where the maximum is also on the side of the eddy to the right of the wind direction. To investigate whether the observed distribution of thunderstorms shows a relationship with the MCAPE differences, and hence with the SST differences, all GPATS detected lightning strike locations in the domain 2 region for the entire 48 -hour analysis periods of each of the four cases are plotted in Figure 7. In the JUN07a case (Figure 7a) a concentration of lightning can be seen over, and south of, the warm eddy with a particularly pronounced area of strikes over the coast in the Newcastle region near $33^{\circ} \mathrm{S}, 152^{\circ} \mathrm{E}$.

382 Comparing with the 48-hour total MCAPE differences in Figure 8, the patches of intense lightning over the southern flank of the central warm eddy occur in a region of generally enhanced MCAPE in JUN07a_BN, however the intense lightning plume near the coast is associated with a localized region of suppressed MCAPE (these regions are almost obscured by lightning 'dots' in the Figure, but can be more easily seen in Figure 6a). There is limited lightning over the cooler waters east of the eddy but significant lightning does occur over the cooler water to the south of the warm eddy. Despite the cooler temperatures there is positive MCAPE difference throughout most of this region. The strong south-eastward flow through this region and consequent displaced MCAPE differences point at a potential relationship

391 between the lightning centred at $34.5^{\circ} \mathrm{S}, 154.5^{\circ} \mathrm{E}$ and the smaller warm eddy at $35.5^{\circ} \mathrm{S}$, 
$392156.5^{\circ} \mathrm{E}$. The plume of lightning strikes that reaches the coast around $33^{\circ} \mathrm{S}$ is associated

393 with the severe and localized weather impacts that this region near Newcastle experienced.

394 This region lies downwind of the largest positive MCAPE differences identified earlier along

395 the southern edge of the warm eddy. Not all regions of increased MCAPE are associated with

396 lightning strikes. An example is the small region at $34^{\circ} \mathrm{S}, 159^{\circ} \mathrm{E}$, which has increased

397 MCAPE but there is no lightning. The relationship between MCAPE and lightning is

398 dependent on many other factors including the presence of a trigger for initializing

399 convection. In this region it is probable that either no trigger was present, or the large-scale

400 forcing was not favourable.

$401 \quad$ For the JUN07b case the lightning occurs over the southeast of the warm eddy with a

402 separate area between $31^{\circ}$ and $33^{\circ} \mathrm{S}$ in the vicinity of $158^{\circ} \mathrm{E}$ (Figure $7 \mathrm{~b}$ ). These areas are

403 generally associated with the edges of positive MCAPE differences, however the average

404 wind flow is blowing from negative to positive MCAPE difference, which is inconsistent

405 with the hypothesis of along flow SST forcing MCAPE release. Figure 5c showed that this

406 case had substantially higher average MCAPE than JUN07a, potentially leading to more

407 rapid thunderstorm development. In this case the vast majority of lightning was

408 predominantly in the first 24 hours of the period, which will be investigated in greater detail

409 in a following section.

410 The most concentrated region of 48-hour lightning in APR12 (Figure 7c) is in an arc

411 centred around $39.5^{\circ} \mathrm{S}, 152^{\circ}$ E. Comparing with the MCAPE differences (Figure 6c) this

412 region can be seen as occurring downstream of the largest MCAPE increases in APR12_OM.

413 A significant amount of lightning occurs over the large region of negative MCAPE

414 differences located south of $36^{\circ} \mathrm{S}$, and between $152^{\circ}$ and $156^{\circ} \mathrm{E}$ but most of this region is

415 downwind of MCAPE reductions. Bands and complexes of thunderstorms associated with

416 storm rainbands lead to a complicated picture. In contrast to JUN07a, this case shows a less 
417 clear relationship between the lightning and the MCAPE differences. The JUN12 case

418 (Figure 7d) had far less lightning than the other cases and the MCAPE differences do not

419 indicate a clear relationship with the SST.

\section{2 hour snapshots}

The focus now turns to investigate the JUN07a case over shorter periods to establish whether SST-induced MCAPE differences and lightning distributions show relationships at timescales closer to those of relevance to different phases of ECL evolution. As the upper level trough moves eastward the instability of the atmosphere generally increases because of the cooling of the upper troposphere. This is one reason why it is important to investigate the MCAPE sensitivity at shorter time-scales. The MCAPE differences (BRAN - Skin) for the four 12-hour periods that make up the 48-hour analysis period are plotted in Figure 9 and the 12-hour lightning strike locations in Figure 10. It should be noted that an analysis of coastal rain gauge observations in Chambers et al. (2014) indicates that the simulated heaviest rainfall occurred roughly 6 hours prior to the observed rainfall. This is an indication that the rainband moved southward earlier in the model that in reality.

For the first 12-hour period (Figure 9a) it is apparent that MCAPE is higher over and west of the warm eddy in JUN07a_BN. Figure 10a shows a small area of lightning just west of the core of the warm eddy during this period at $32^{\circ} \mathrm{S}, 154.5^{\circ} \mathrm{E}$. In the second 12 -hour period the largest MCAPE differences occur along the southern flank of the warm eddy with increases of over $400 \mathrm{~J} \mathrm{~kg}^{-1}$ (Figure 9b). This occurs in a region broadly consistent with the concentrated lightning during this period. The area of greatest MCAPE increase occurs slightly south of the lightning, consistent with a more southward location of the rainband by this time.

In the third time period, lightning data in Figure 10c show a plume of lightning 441 propagating towards the coast and originating over the region of strong SST gradients. The 
region of elevated CAPE has propagated further south (Figure 9c). A large region of lowered

443 CAPE, that originates over the cooler water to the east of the warm eddy and is evident at all

444 of the time periods, is most pronounced in the third period. By the fourth time period the

445 CAPE over the warm eddy appears to have recovered somewhat while the southward

446 propagating elevated region has spread further south.

As mentioned earlier, the JUN07a simulations had a 6 hour discrepancy in the timing

448 of peak coastal rainfall. In an attempt to take account of this, an additional 12-hour MCAPE

449 difference plot is in Figure 11, where the 12-hour periods for calculating the MCAPE are 6

450 hours earlier than the lightning periods. This plot shows a more clear consistency between the

451 location of increased MCAPE and of lightning strikes associated with a more accurate

452 location of the principal rainband. In particular Figure 11c shows that the plume of

453 thunderstorms that impacted the coast so severely occur in a narrow band of increased

454 MCAPE. The relationship is complicated by the fact that the occurrence of thunderstorms

455 releases CAPE and so if enough storms occur then the MCAPE will decrease. These results

456 show that at a 12-hourly timescale, and accounting for the 6 hour discrepancy with

457 observations, the effect of introducing eddy resolving SSTs is to increase CAPE in regions

458 generally associated with regions of observed thunderstorms.

\section{3-hour analysis}

To continue the shift down to smaller timescales, an analysis of the 3-hourly lightning

strikes and MCAPE difference over the period over which significant coastal impact occurred

462 (1800 UTC 7 June to 0600 UTC 8 June) has been conducted. 3-hourly timescales are more representative of a thunderstorm complex lifecycle and so are used to look at the instability sensitivity for specific periods of intense thunderstorm activity. At these timescales it is

465 essential to take account of the 6 hour error in the timing of simulated heaviest coastal

466 rainfall. Therefore the MCAPE difference plots are made for 3-hourly periods that starts 6 
467 hours earlier than the beginning of each 3-hour lightning period. A potential source of error in 468 this type of analysis could come because of changes to the MCAPE due to the diurnal cycle, 469 however diurnal radiative forcing should be less significant over this region at this time of 470 year (winter). The results of this analysis for four 3-hour periods is shown in Figure 12. For 471 the first two periods (Figure 12a and b) an area of strongly enhanced MCAPE in JUN07a_BN

472 (up to and over $400 \mathrm{~J} \mathrm{~kg}^{-1}$ ) can be seen to be propagating southward (with embedded westward propagating regions). Associated with the southern and western sides of this region are areas of concentrated lightning. Figure 12c shows that the lightning extended westward in a plume from the middle of the three lightning patches in the prior 3-hour period. By comparing Figure $12 \mathrm{~b}$ and $\mathrm{c}$ the intense lightning plume can be seen to develop downwind of the area of greatest enhanced MCAPE located along $33^{\circ} \mathrm{S}$ between $153^{\circ}$ and $156^{\circ} \mathrm{E}$. In the final 3-hour period the intense lightning continues in this plume and is associated with elevated coastal and upwind MCAPE while regions of suppressed MCAPE occur to the north and south. Figure 12d shows that the largest MCAPE increases over land of the four periods occur in the final period near $33^{\circ} \mathrm{S}, 152^{\circ} \mathrm{E}$.

\section{Discussion}

This research compares lightning data with model MCAPE differences caused by changing the SST input data in an investigation into potential relationships between complex SST structures in the EAC and thunderstorms during ECLs. This was motivated initially by comparisons made between the distribution of lightning and the distribution of SST (for example Figure 7) that suggested a connection between the two. It is also physically motivated since, prior to significant vertical mixing of air, an air mass moving over water would be expected to become more unstable more quickly if SSTs are warmer because warmer waters imply greater surface fluxes of heat and moisture into the boundary layer. 
491 Hypothetically the instability should continue to increase unless the low-level air mixes 492 upward and warms the middle and upper layers of the troposphere or if the low-level air 493 reaches thermal and moist near-equilibrium with the ocean surface that prevents further 494 increases in near-surface moist static energy. On the 48-hour average MCAPE differences in 495 Figure 6, there is evidence of this process emerging with MCAPE tending to be larger on the 496 downwind side of areas of warmer waters in the detailed SST runs. However there are a 497 number of other complicating factors to consider with respect to this process, three of which 498 we discuss below.

The first complication comes from the effect changes in SST can have on the surface

500 wind speed. Past research (see review by Small et al 2008) suggests that surface winds tend 501 to increase over warm water because greater vertical thermal instability mixes momentum 502 from aloft down to the surface. If this is assumed to be the case then this effect will change 503 the vertical wind shear profile which is known to be important for thunderstorm development 504 and severity. There is a further surface wind complication that is not generally considered in 505 the previous research which concerns situations where the momentum aloft is weaker than, or 506 opposing, the surface flow. In these situations the vertical mixing of momentum over warmer waters should decrease the surface winds, not increase them, with consequent vertical wind 508 shear changes. A second complication issue is associated with the formation of the thunderstorms

510 themselves. In a classic thunderstorm situation the thunderstorm will be triggered once 511 warming and moistening of the boundary layer is enough for a lifted parcel to overcome 512 convective inhibition. Once the thunderstorm occurs it will tend to warm the middle and 513 upper troposphere and consequently reduce the CAPE. It is therefore not difficult to imagine 514 situations where warmer water areas are associated with reduced CAPE caused by areas of 515 moist convection triggered by the same, or other areas of warmer waters. 
517 processes such as baroclinic instability. The APR12 case stands out as the most prominent

518 example of the four cases that exhibited complications of this kind. In this case the storm was

519 more compact and intense in APR12_OM than in APR12_skin and this impacted the

520 distributions of MCAPE differences substantially, particularly in the later hours of the

521 simulations.

With these considerations in mind the lightning data analysis reveals a complicated

but at times marked relationship between eddy and filament structures in the EAC. On the 48displacement of MCAPE difference from SST difference occurring in regions consistent with low level heat and moisture advection. The effect of the complex SST patterns is to rearrange the pattern of MCAPE across the region and we hypothesize that this process also re-arranges the distribution of thunderstorms. Further evidence for this hypothesis is found when shorter timescales, more relevant to thunderstorm processes, are considered. The 3-hourly analysis of 530 the JUN07a case during the period of greatest coastal impact shows that regions of elevated

531 MCAPE associated with changing the SST occur in regions consistent with lightning activity.

532 On these shorter timescales increased MCAPE associated with changing the SST shows less of a correlation with SST differences.

The 3-hourly results emphasize the importance of including accurate SSTs in future numerical forecasts of similar events on this fine scale. The results suggest that the instability

536 in the thunderstorm band was significantly increased because of the warm eddy present

537 offshore. The effect of the eddy and associated SST gradients along its southern flank increase the convectively instability and focus it into a narrow band in a consistent location with respect to the observed thunderstorm band. The significant damaging impacts were

540 largely associated with this focussed thunderstorm band despite the fact that the low pressure 
541 system covered a much broader region. Since the model results suggest this region may be more favourable for thunderstorms in the BRAN simulations through increased MCAPE, it is evidence that this highly significant storm feature was directly triggered by the warm eddy

544 and associated strong SST gradient.

Past research on the effect of SST gradients on surface winds has shown that

546 convergence tends to occur when air flows from a warm to a cold sea surface (e.g. Sweet et

547 al. 1981). Given this relationship, the maximum in MCAPE difference seen on the 48-hour average in JUN07a in Figure 6a along the southern edge of the warm eddy could be explained by a couple of factors. The first is that on the low-level flow trajectory beyond this point (to

550 the south), the MCAPE tends to release because the convergence over the strong SST gradient provides enough uplift to trigger deep convection. This is consistent with KuwanoYoshida et al. (2010) who found evidence of deep convection and thunderstorms preferentially occurring over strong SST gradients. Under the northwest average flow over the eddy, the southern edge of the eddy has a tendency to be the final point on the trajectory that built up MCAPE across the warm eddy, and therefore should have the highest MCAPE value. The second influence might be from higher moisture content within a region of moisture convergence forced by the SST gradient. This should increase the dew point temperature that will tend to increase the MCAPE (all other factors remaining equal). This complicated process will require further detailed work and analysis. positive MCAPE differences. This region is also where the low pressure intensified and on initial impression it appears that the low tracks along the SST gradient on the edge the eddy (not shown). Despite this impression the JUN12_Skin simulation, that does not resolve an

564 eddy in this location, produced a very similar track and reached a similar intensity to

565 JUN12_BN. This point is made because it suggests that in this case the impression of a track 
566 along an SST gradient may not be causal (as suggested by Holland et al. 1987 for a similar case) but coincidental and instead possibly governed by other factors such as synoptic or topographic steering.

Overall, a cold pool of air in the middle troposphere associated with ECL

570 development moving over a focussed region of warm water is conducive to vertical

571 instability that will be released where there is a convective trigger. This release happens

572 within broad scale storm triggers such as fronts, rainbands, topography, and as this study thunderstorm development during ECLs is not straightforward, but is compelling. For the most damaging case, the results strongly indicate that the severe thunderstorm rainband was intensified because of the large warm offshore eddy and its associated southern side strong SST gradient.

\section{Conclusion}

579 The relationship between thunderstorm distributions and SST has been investigated using

580 lightning data and WRF simulations for four ECLs. WRF simulations initialised with coarse

581 SSTs are compared with detailed SST runs. Complex eddy and frontal structures in the

582 detailed SST runs cause MCAPE increases associated with regions of warmer SST and

583 decreases associated with colder SST. There is evidence that horizontal heat and moisture

584 advection displaces the MCAPE changes downwind. At 3 hour timescales, the differences in

585 MCAPE become larger and more localized and show a compelling correlation with the observed lightning. The focused study of the 7-9 June 2007 case has shown that the plume of

587 thunderstorms associated with the coastal damage occurs downwind of the region of

588 enhanced MCAPE on the southern flank of the EAC warm eddy present at the time. 
589 It is concluded that the complex upper ocean heat content structure present during this case

590 significantly influenced the impact from thunderstorms. Therefore an accurate eddy resolving

591 SST dataset may be important for accurate forecasts of future storms of similar nature.

\section{$592 \quad$ Acknowledgments}

593 This research is funded by Lloyd's Register Foundation (LRF), a UK registered charity and 594 sole shareholder of Lloyd's Register Group Ltd, which invests in science, engineering and 595 technology for public benefit, worldwide. Prasanth Divakaran provided valuable help in

596 working with the BRAN data. The University of Melbourne provided additional financial

597 support for this work. This work forms part of an international research network headed by

598 Prof. Jinyu Sheng of Dalhousie University, investigating extreme marine events.

\section{References}

600 Alexander GD Weinman JA Karyampudi VM Olson WS Lee ACL (1999) The effect of

601 assimilating rain rates derived from satellites and lightning on forecasts of the 1993

602 superstorm. Mon Weather Rev 127:1433-1457

603

604 Andrews JC Scully-Power P (1976) The structure of an East Australian Current anticyclonic 605 eddy. J Phys Oceanogr 6:756-765

606

607 Abarca SF Corbosiero KL (2011) The World Wide Lightning Location Network and 608 convective activity in tropical cyclones. Mon Weather Rev 139:175-191

609 
610 Betts AK Miller MJ (1986) A new convective adjustment scheme. Part II: Single column

611 tests using GATE wave, BOMEX, and Arctic air-mass data sets. Q J R Meteorol Soc

$612 \quad 112: 693-709$

613

614 Black RA Hallett J (1999) Electrification in hurricanes. J Atmos Sci 56:2004-2028

615

616 Brassington GB Summons N Lumpkin R (2011) Observed and simulated Lagrangian and

617 eddy characteristics of the East Australian Current and the Tasman Sea. Deep Sea Res

$618 \quad 58: 559-573$

619

620 Brassington GB et al (2012) Ocean Model, Analysis and Prediction System version 2.

621 CAWCR Tech Rep 52 http://www.cawcr.gov.au/publications/technicalreports/CTR_052.pdf.

622 Accessed 13 August 2014

623

624 Bridgman H (1985) The Sygna storm at Newcastle-12 years later. Meteorol Aust 3:10-16

625

626 Browning SA Goodwin ID (2013) Large-scale influences on the evolution of winter

627 subtropical maritime cyclones affecting Australia's east coast. Mon Weather Rev 141:2416-

$628 \quad 2431$

629

630 Buechler DE Christian HJ Goodman SJ (1994) Rainfall estimation using lightning data.

631 Seventh Conf on Satell Meteorol and Oceanogr, Monterey, CA, Amer Meteorol Soc, June 6-

$63210,171-174$

633 
634 Cecil DJ Zipser EJ (1999) Relationships between tropical cyclone intensity and satellite-

635 based indicators of inner core convection: $85-\mathrm{GHz}$ ice-scattering signature and lightning.

636 Mon Weather Rev 127:103-123

637

638 Chambers CRS Brassington GB Simmonds I Walsh K (2014) Precipitation changes due to

639 the introduction of eddy-resolved sea surface temperatures into simulations of the "Pasha

640 Bulker" Australian east coast low of June 2007. Meteorol Atmos Phys 125:1-15 doi:

$641 \quad 10.1007 / \mathrm{s} 00703-014-0318-4$

642

643 Chang D-E Weinman JA Morales CA Olson WS (2001) The effect of spaceborne microwave

644 and ground-based continuous lightning measurements on forecasts of the 1998 Groundhog

645 Day storm. Mon Weather Rev 129:1809-1833

646

647 Christian HJ et al (2003) Global frequency and distribution of lightning as observed from

648 space by the Optical Transient Detector. J Geophys Res 108:4005

649

650 Colman BR (1990) Thunderstorms above frontal surfaces in environments without positive

651 CAPE. Part I: A climatology. Mon Weather Rev 118:1103-1121

652

653 Cummins KL Murphy MJ (2009) An overview of lightning locating systems: History,

654 techniques, and data uses, with an in-depth look at U.S. NLDN.IEEE Trans Electromagn

655 Compat 51:499-518

656

657 DeMaria M DeMaria RT Knaff JA Molenar D (2012) Tropical cyclone lightning and rapid 658 intensity change. Mon Weather Rev 140:1828-1842 
660 Dowdy AJ Mills GA Timbal B Wang Y (2013a) Changes in the risk of extratropical cyclones 661 in eastern Australia. J Clim 26:1403-1417

662

663 Dowdy AJ Mills GA Timbal B (2013b) Large-scale diagnostics of extratropical cyclogenesis 664 in eastern Australia. Int J Climatol 33:2318-2327

665

666 Dudhia J (1989) Numerical study of convection observed during the Winter Monsoon

667 Experiment using a mesoscale two-dimensional model. J Atmos Sci 46:3077-3107

668

669 Evans JL Guishard MP (2009) Atlantic subtropical storms. Part I: Criteria and composite 670 analysis. Mon Weather Rev 137:2065-2080

671

672 Fandry CB Leslie LM (1984) A two-layer quasi-geostrophic model of summer trough

673 formation in the Australian subtropical easterlies. J Atmos Sci 41:807-818

674

675 Global Climate and Weather Modeling Branch (2003) The GFS atmospheric model. NCEP

676 Off Note 442 http://www.emc.ncep.noaa.gov/officenotes/newernotes/on442.pdf. Accessed 13

677 August 2014.

678

679 GPATS (2013) Global Position and Tracking Systems, a revolution in lightning detection and 680 warning technology. http://www.gpats.com.au. Accessed 13 August 2014

681

682 Griffies SM Harrison MJ Pacanowski RC Rosati A (2004) A technical guide to MOM4.

683 GFDL Ocean Group Tech Rep 5 
684

685 Hamon BV (1965) The East Australian Current, 1960-1964. Deep-Sea Res 12:899-921

686

687 Hart RE (2003) A cyclone phase space derived from thermal wind and thermal asymmetry.

688 Mon Weather Rev 131:585-616

689

690 Hobbs PV (1987) The Gulf-Stream rainband. Geophys Res Lett 14:1142-1145

691

692 Holland GJ Lynch AH Leslie LM (1987) Australian east-coast cyclones. Part 1: Synoptic 693 overview and case study. Mon Weather Rev 115:3024-3036.

694

695 Hong S-Y Noh Y Dudhia J (2006) A new vertical diffusion package with an explicit

696 treatment of entrainment processes. Mon Weather Rev 134:2318-2341

697

698 Janjic ZI (1994) The step-mountain eta coordinate model: Further developments of the

699 convection, viscous sublayer, and turbulence closure schemes. Mon Weather Rev 122:927-

$700 \quad 945$

701

702 Kuwano-Yoshida A Minobe S Xie S-P (2010) Precipitation response to the Gulf Stream in an

703 atmospheric GCM. J Clim 23:3676-3698

704

705 Li Y Carbone RE (2012) Excitation of rainfall over the tropical western Pacific.

$706 \quad J$ Atmos Sci 69:2983-2994

707 
708 Li X Zheng W Pichel WG Zou C-Z Clemente-Colón P Friedman KS (2004) A cloud line 709 over the Gulf Stream. Geophys Res Lett 31:14

710

711 McInnes KL Leslie L McBride J (1992) Numerical simulation of cut-off lows on the

712 Australian East Coast: Sensitivity to sea-surface temperature. Int J Climatol 12:783-795

713

714 Mills GA Webb R Davidson NE Kepert J Seed A Abbs D (2010) The Pasha Bulker east coast

715 low of 8 June 2007. CAWCR Tech Rep 023

716

717 Minobe S Kuwano-Yoshida A Komori N Xie S-P Small RJ (2008) Influence

718 of the Gulf Stream on the troposphere. Nature 452:206-209

719

720 Miyama T Nonaka M Nakamura H Kuwano-Yoshida A (2012) A striking early-

721 summer event of a convective rainband persistent along the warm Kuroshio in the East China

722 Sea. Tellus A 64:18962

723

724 Mlawer EJ Taubman SJ Brown PD Iacono MJ Clough SA (1997) Radiative transfer for

725 inhomogeneous atmosphere: RRTM, a validated correlated-k model for the longwave. J

726 Geophys Res 102:16663-16682

727

728 Moncrieff MW Miller MJ (1976) The dynamics and simulation of tropical cumulonimbus

729 and squall lines. Q J R Meteorol Soc 120:373-94

730

731 Oke PR Brassington GB Griffin DA Schiller A (2008) The Bluelink ocean data assimilation

732 system (BODAS). Ocean Model 21:46-70 
734 Orville RE Vonnegut B (1974) Lightning detection from satellites. In: Dolezalek H Reiter R

735 (eds) Electrical processes in atmospheres. Steinkopff Verlag, pp 750-753

736

737 Orville RE Henderson RW Basart LF (1983) An east coast lightning detection network. Bull

738 Am Meteorol Soc 64:1029-1037

739

740 Pepler AS Di Luca A Ji F Alexander LV Evans JP Sherwood SC (2014) Impact of

741 identification method on the inferred characteristics and variability of Australian East Coast

742 Lows. Mon Weather Rev 143:864-877

743

744 Pessi A Businger S (2009) Relationships between lightning, precipitation, and hydrometeor

745 characteristics over the North Pacific Ocean. J Appl Meteorol Climatol 48:833-848

746

747 Qi L Leslie L Speer M (2006) Climatology of cyclones over the southwest Pacific: 1992-

748 2001. Meteorol Atmos Phys 91:201-209

749

750 Rutledge SA Williams ER Keenan TD (1992) The Down Under Doppler and Electricity

751 Experiment (DUNDEE): Overview and preliminary results. Bull Am Meteorol Soc 73:3-16

752

753 Sasaki YN Minobe S Minobe T Asai T Inatsu M (2012) Influence of the Kuroshio in the East

754 China Sea on the early summer (Baiu) rain. J Clim 25:6627-6645

755 
757 Eddy-resolving ocean circulation in the Asian-Australian region inferred from an ocean reanalysis effort. Prog Oceanogr 76:334-365

759

760 Skamarock WC Klemp JB Dudhia J Gill DO Barker DM Wang W Powers JG (2005) A

761 description of the Advanced Research WRF Version 2. NCAR Tech Note 468

762

763 Small TJ et al (2008) Air-sea interaction over ocean fronts and eddies. Dyn Atmos Oceans

$764 \quad 45: 274-319$

765

766 Squires K Businger S (2008) The morphology of eyewall lightning outbreaks in two 767 category-5 hurricanes. Mon Weather Rev 136:1706-1726.

768

769

Stammer D (1997) Global characteristics of ocean variability from regional TOPEX/

770 POSEIDON altimeter measurements. J Phys Oceanogr 27:1743-1769

771

772

Sweet W Fett R Kerling J Violette PL (1981) Air-sea interaction effects in the lower troposphere across the north wall of the Gulf Stream. Mon Weather Rev 109:1042-1052

774

Tanimoto Y Kanenari T Tokinaga H Xie S-P (2011) Sea level pressure minimum along the Kuroshio and its extension. J Clim 24:4419-4434

777

778 Thompson G Rasmussen RM Manning K (2004) Explicit forecasts of winter precipitation

779 using an improved bulk microphysics scheme. Part I: Description and sensitivity analysis.

780 Mon Weather Rev 132:519-542 
782 Trunk TJ Bosart LF (1990) Mean radar echo characteristics during project GALE. Mon

783 Weather Rev 118:459-469

784

785 Vianna ML Menezes VV Pezza AB Simmonds I (2010) Interactions between Hurricane

786 Catarina (2004) and warm core rings in the Southern Atlantic Ocean. J Geophys Res 115:

$787 \quad \mathrm{C} 07002$

788

789

Warner TT Lakhtakia MN Doyle JD (1990) Marine atmospheric boundary layer circulations

790 forced by Gulf Stream sea surface temperature gradient. Mon Weather Rev 118:309-323

791

792

Weisman ML Skamarock WC Klemp JB (1997) The resolution dependence of explicitly

793

modeled convective systems. Mon Weather Rev 125:527-548

794

795

796

Williams ER Rutledge SA Geotis SG Renno N Rasmussen E Rickenbach T (1992) A radar and electrical study of tropical “'hot towers.” J Atmos Sci 49:1386-1395

797

798

Xu H Xu M Xie S-P Wang Y (2011) Deep Atmospheric Response to the Spring Kuroshio

799 over the East China Sea. J Clim 24:4959-4972.

800

801

Tables and figures

802 Table 1: WRF simulation names, dates, and SST data used.

\begin{tabular}{|l|l|l|}
\hline Case name & Dates & SST data input \\
\hline JUN07a_skin & 1200 UTC 6 to 0000 UTC 9 June 2007 & NCEP skintemps \\
\hline
\end{tabular}




\begin{tabular}{|l|l|l|}
\hline JUN07a_BN & & BRAN \\
\cline { 1 - 1 } JUN07b_skin & \multirow{2}{*}{ 0000 UTC 15 to 1200 UTC 17 June 2007 } & NCEP SSTs \\
\cline { 1 - 1 } JUN07b_BN & & BRAN \\
\cline { 1 - 1 } APR12_skin & \multirow{2}{*}{ 1200 UTC 23 to 0000 UTC 26 April 2012 } & NCEP skintemps \\
\cline { 1 - 1 } APR12_OM & & OceanMAPS \\
\cline { 1 - 1 } JUN12_skin & \multirow{2}{*}{ 0000 UTC 3 to 1200 UTC 5 June 2012 } & NCEP skintemps \\
\cline { 1 - 1 } & & OceanMAPS \\
\hline
\end{tabular}

803

$140 \mathrm{E}$ $150 \mathrm{E}$

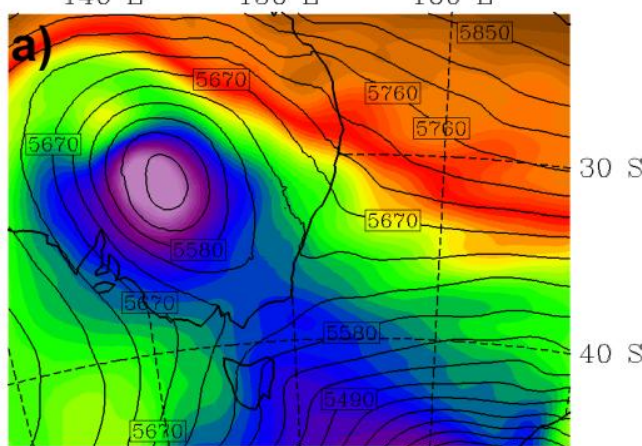

$140 \mathrm{E}$

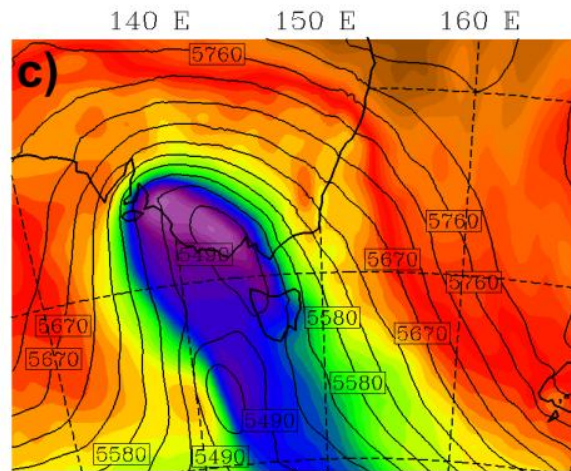

$140 \mathrm{E}$ $150 \mathrm{E}$

$160 \mathrm{E}$

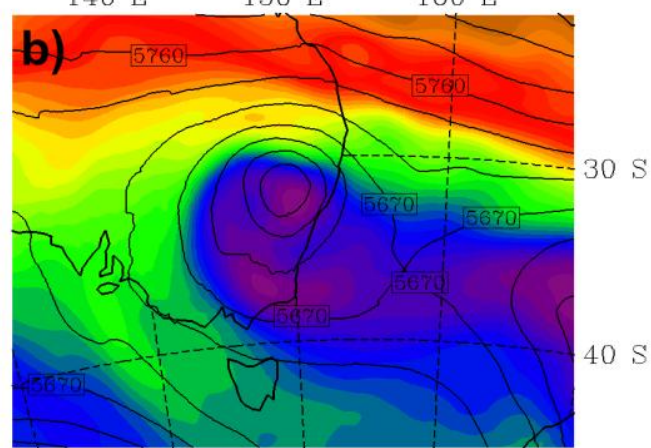

$140 \mathrm{E} \quad 150 \mathrm{E} \quad 160 \mathrm{E}$

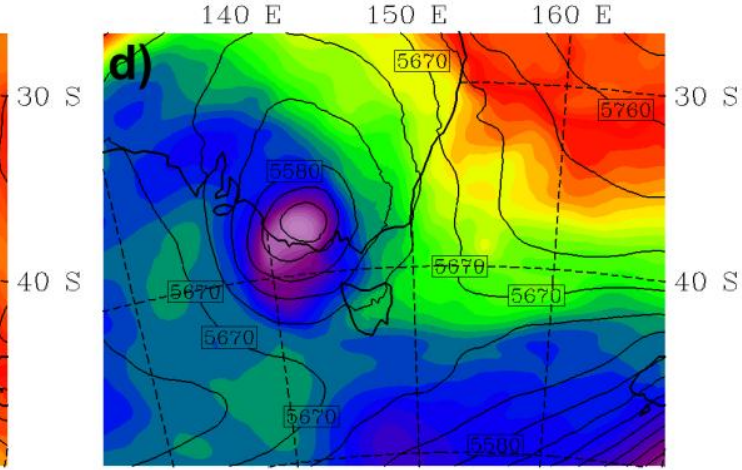

804

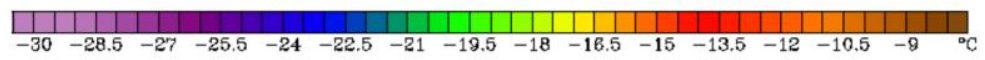

Figure 1: Initial domain $1500 \mathrm{hPa}$ temperatures $\left({ }^{\circ} \mathrm{C}\right)$ and heights (m) for each case; a) 1200

UTC 6 June 2007, b) 0000 UTC 15 June 2007, c) 1200 UTC 23 April 2012, and d) 0000

UTC 3 June 2012. 


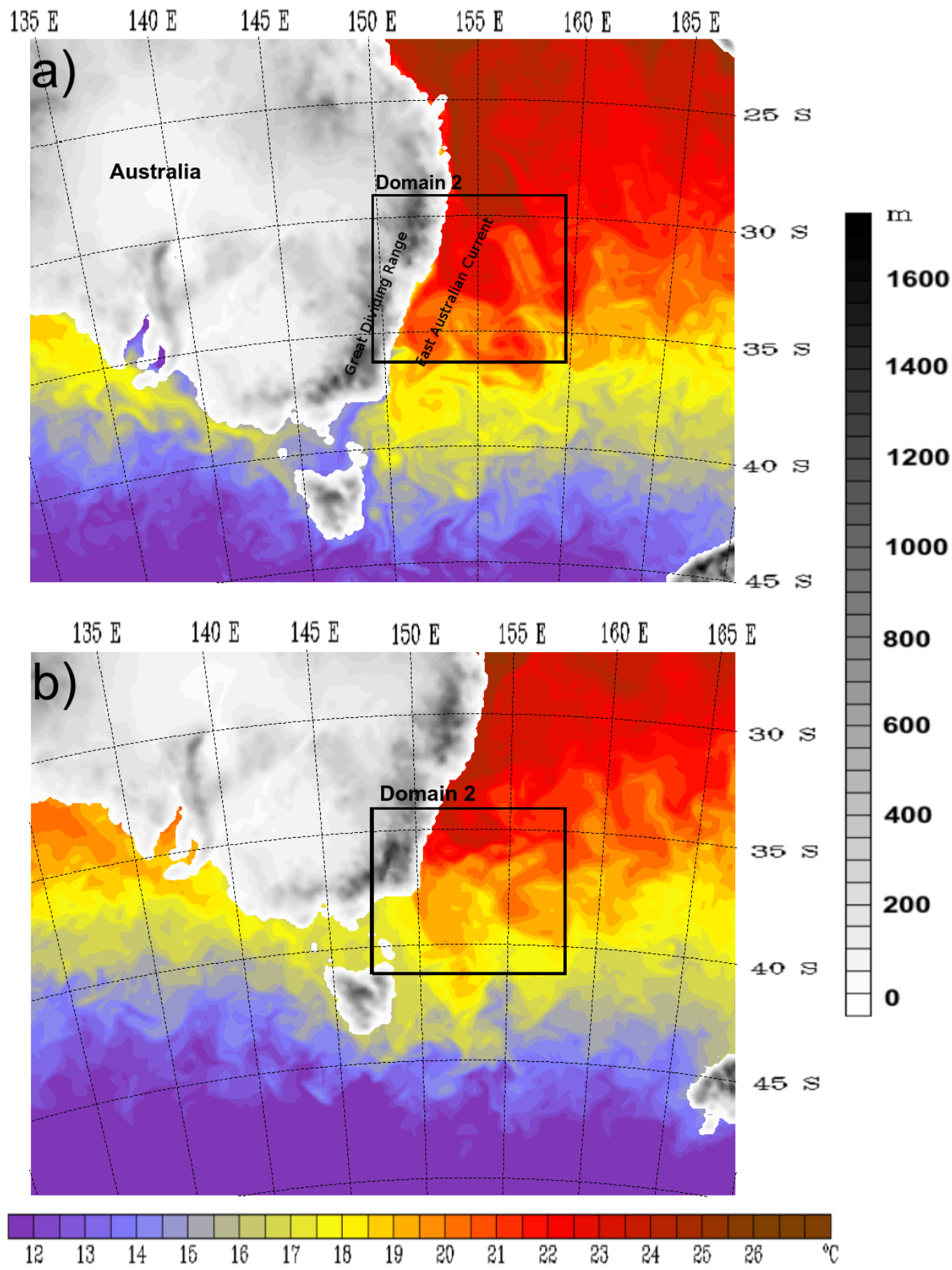

Figure 2: $15 \mathrm{~km}$ (whole map) and $3 \mathrm{~km}$ (inner box) resolution domains with terrain height (m) for a) the 2007 cases (with BRAN SST for 1200 UTC 6 June 2007 plotted over the ocean), and b) the 2012 cases (with OceanMAPS SST for 1200 UTC 23 April 2012 plotted over the ocean). 

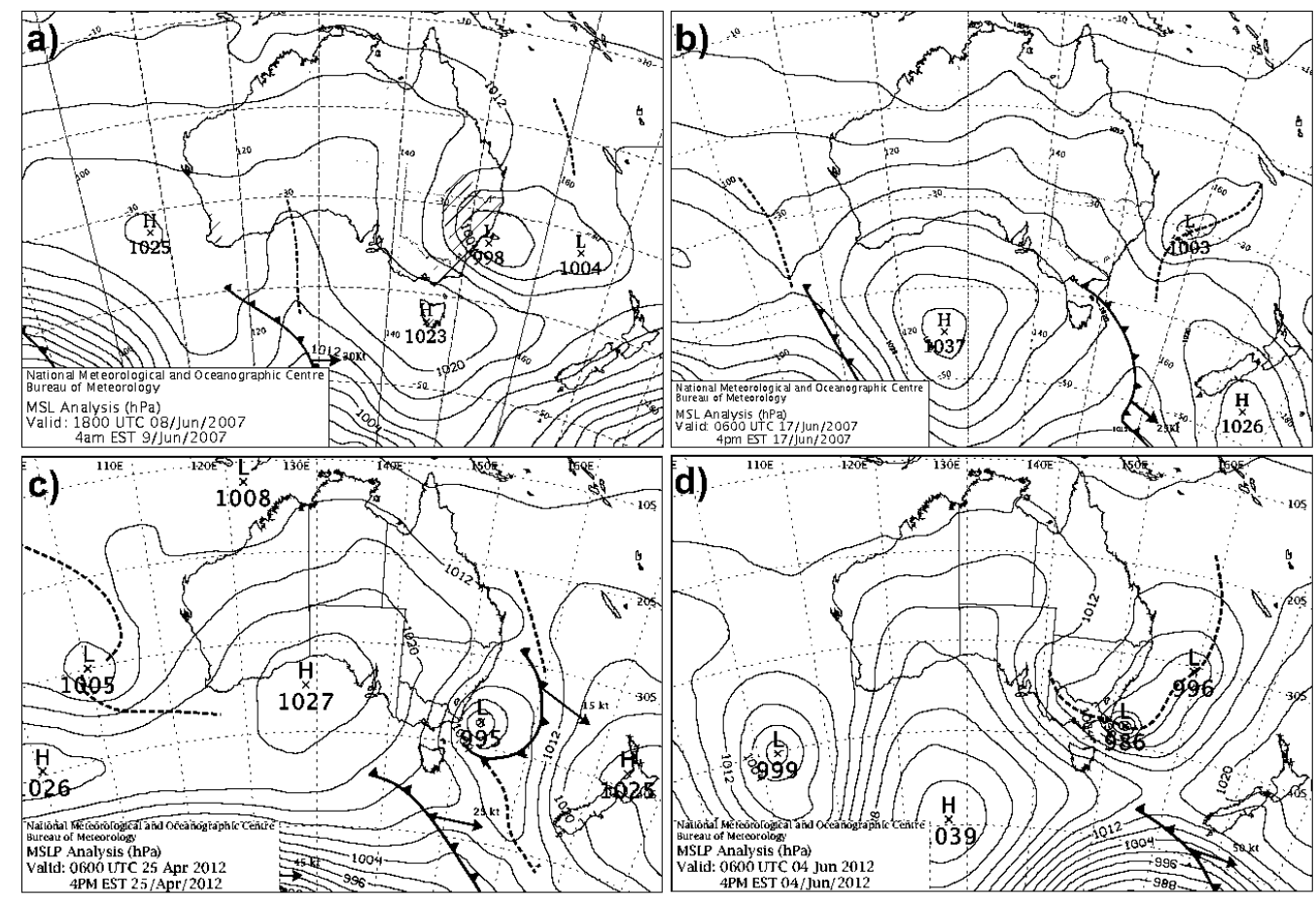

Figure 3: Sea level pressure analyses from the National Meteorological and Oceanographic

Centre, Australian Bureau of Meteorology for the time of lowest analysed sea level pressure for each case; a) 1800 UTC 8 June 2007, b) 0600 UTC 17 June 2007, c) 0600 UTC 25 April 2012, and d) 0600 UTC 4 June 2012. Hatched areas indicate rainfall. 

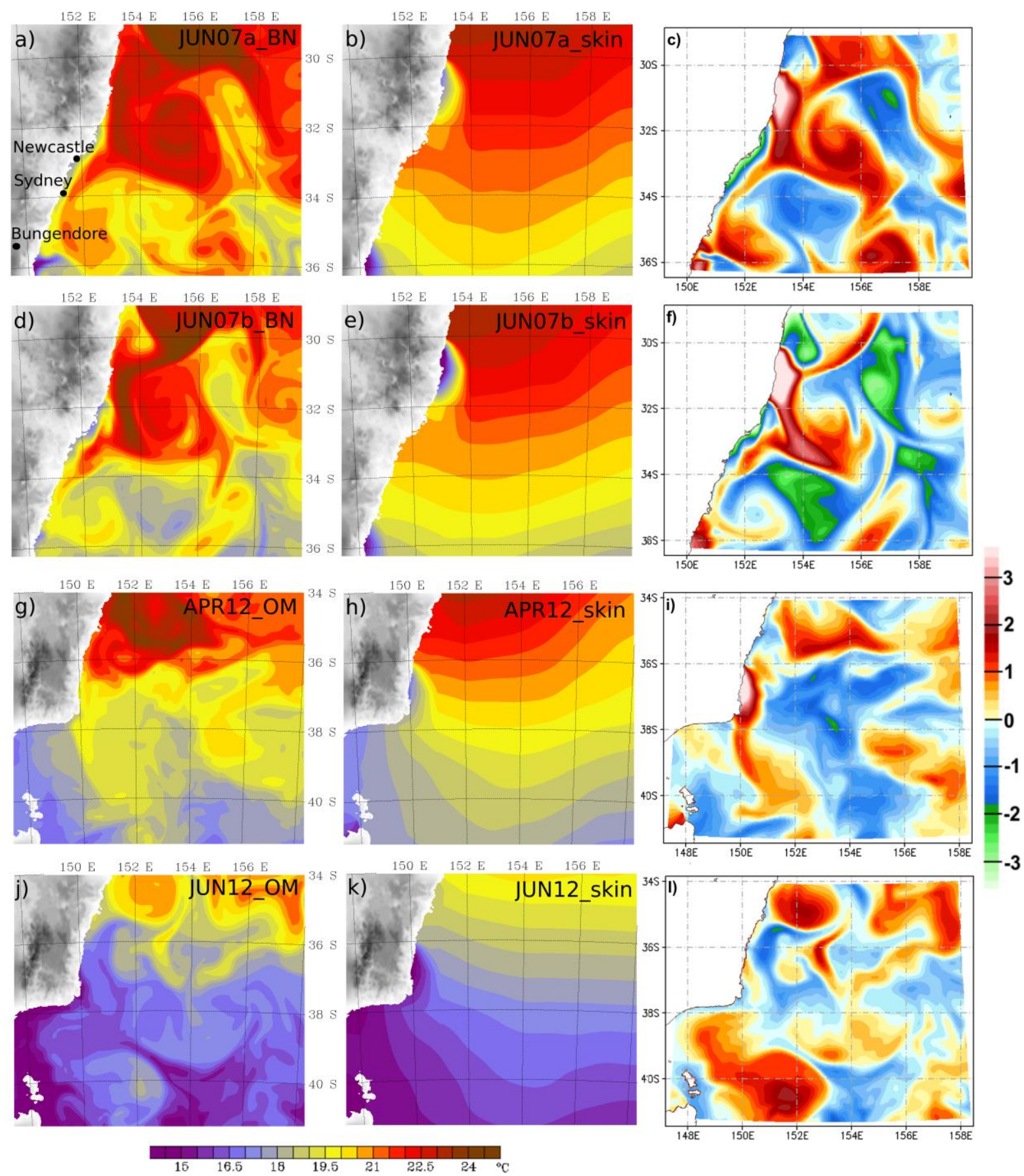

Figure 4: Comparison of initial domain 2 SST inputs into each of the WRF simulations

(labelled in top right, refer to Table 1) for 1200 UTC 6 June 2007 [a) and b)], 0000 UTC 15 June 2007 [d) and e)], 1200 UTC 23 April 2012 [g) and h)], and 0000 UTC 3 June 2012 [j) and k)]. In the right column are the 48-hour averaged SST differences (detailed - skin, ${ }^{\circ} \mathrm{C}$ ) for the analysis period of each case. 

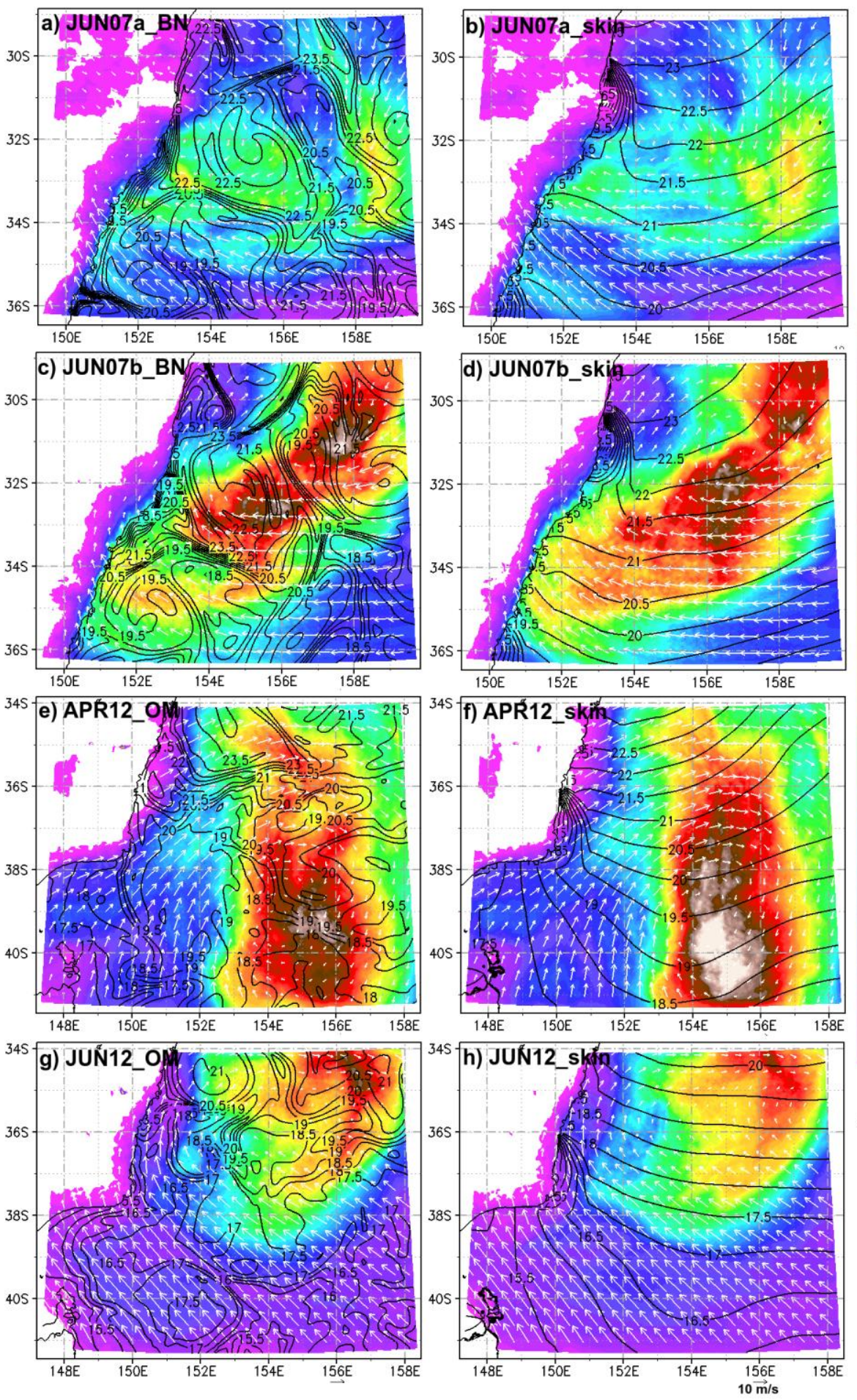

400

200

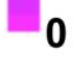

$\mathrm{J} / \mathbf{k g}$

Figure 5: 48-hour averaged MCAPE $\left(\mathrm{J} \mathrm{kg}^{-1}\right.$, colours), $\operatorname{SST}\left({ }^{\circ} \mathrm{C}\right.$, black contours $)$, and 10-metre wind vectors $\left(\mathrm{m} \mathrm{s}^{-1}\right.$, representative $10 \mathrm{~m} \mathrm{~s}^{-1}$ vector in bottom right) for the cases as labelled in the top left of each panel. 

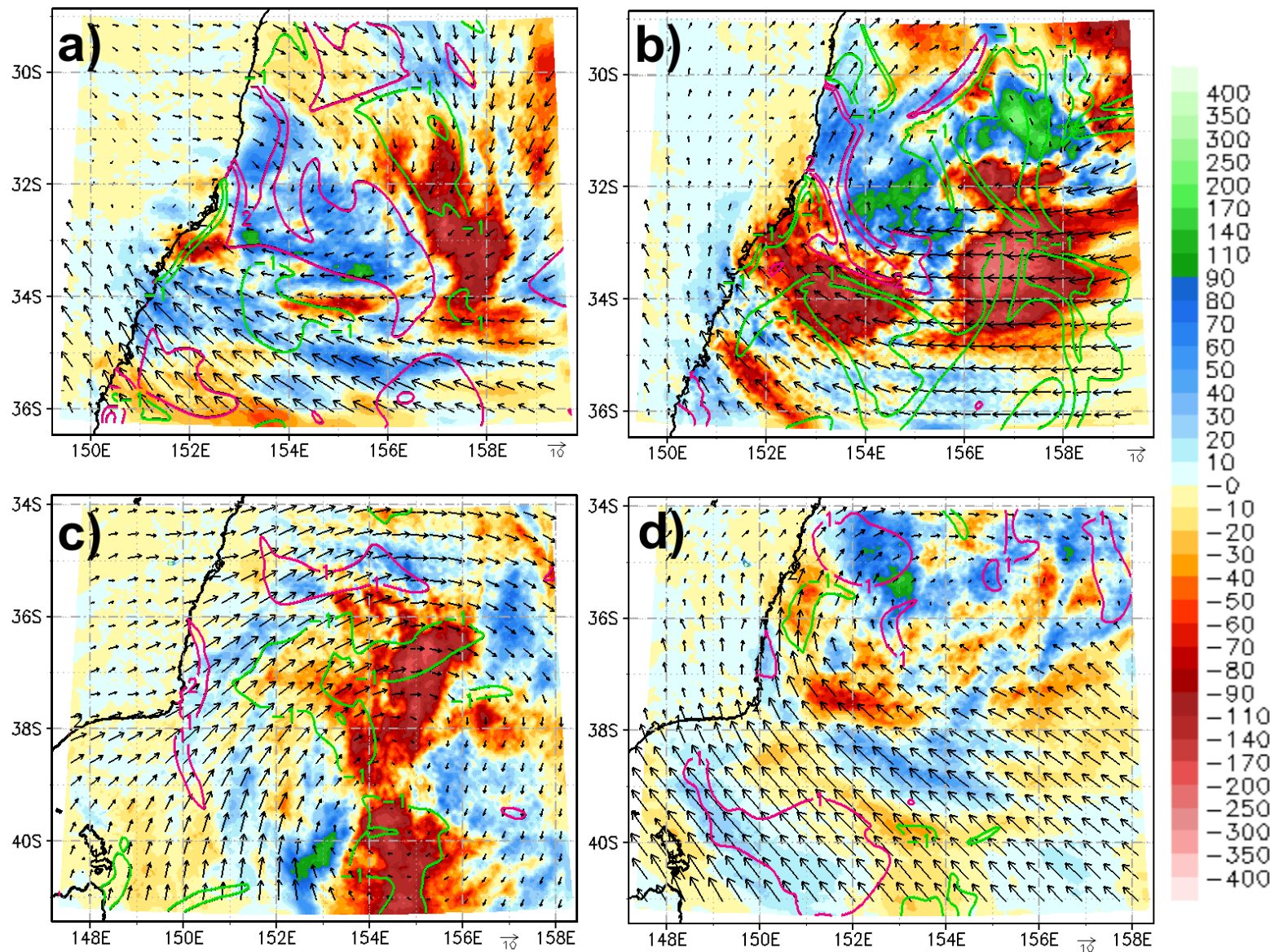

Figure 6: 48-hour average MCAPE differences (colours) and SST differences (magenta for +1 and $+2{ }^{\circ} \mathrm{C}$ and green for -1 and $-2{ }^{\circ} \mathrm{C}$ ) for a) JUN07a_BN - JUN07a_skin b) JUN07b_BN - JUN07b_skin c) APR12_OM - APR12_skin and d) JUN12_OM - JUN12_skin. The 48hour average 10 metre wind vectors for the detailed runs are overlaid $\left(\mathrm{m} \mathrm{s}^{-1}\right.$, representative vector in bottom right). 

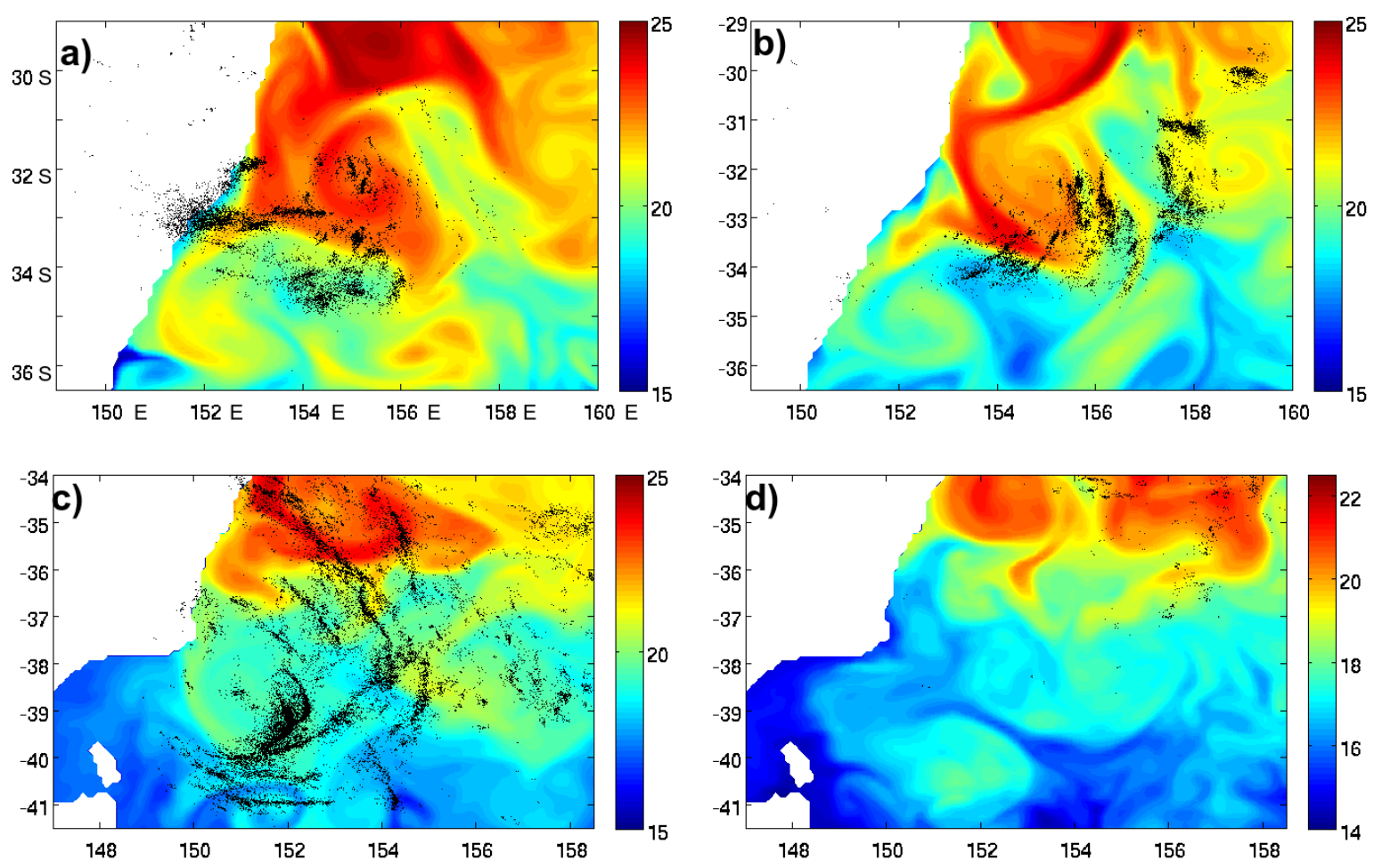

Figure 7: 48-hour total detected Global Position and Tracking System (http://www.gpats.com.au) lightning strikes (black dots) for a) 0000 UTC 7 June to 0000 UTC 9 June 2007, b) 1200 UTC 15 June to 1200 UTC 17 June 2007, c) 0000 UTC 24 April to 0000 UTC 26 April 2012, and b) 1200 UTC 3 June to 1200 UTC 5 June 2012. Daily BRAN (for 2007 cases) or OceanMAPS (for 2012 cases) SST is plotted in colour for the initial day in each period. 


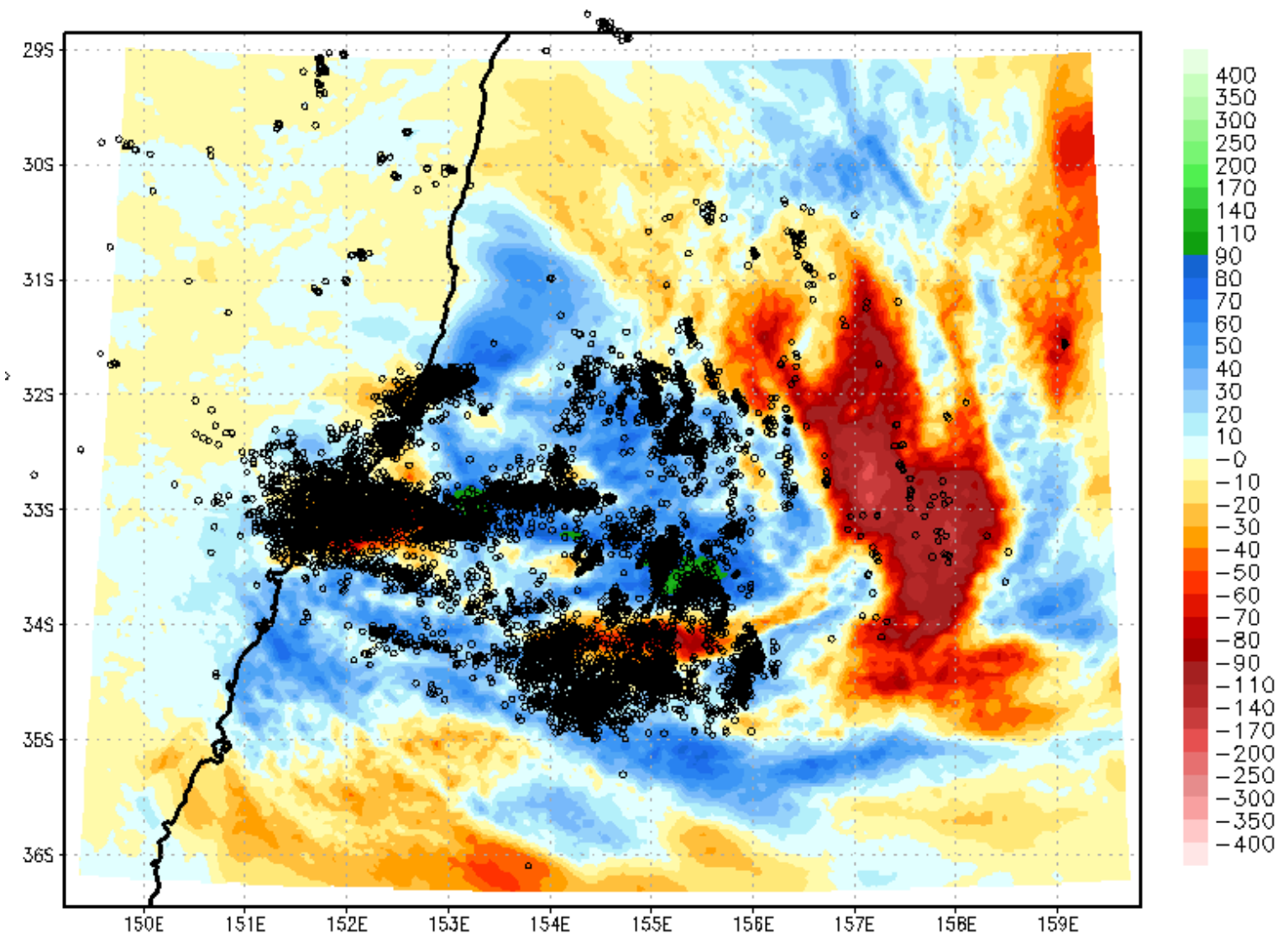

Figure 8: JUN07a 48-hour MCAPE difference (JUN07a_BN - JUN07a_skin, $\mathrm{J} \mathrm{kg}^{-1}$ ) and GPATS observed lightning strike locations (black circles). 


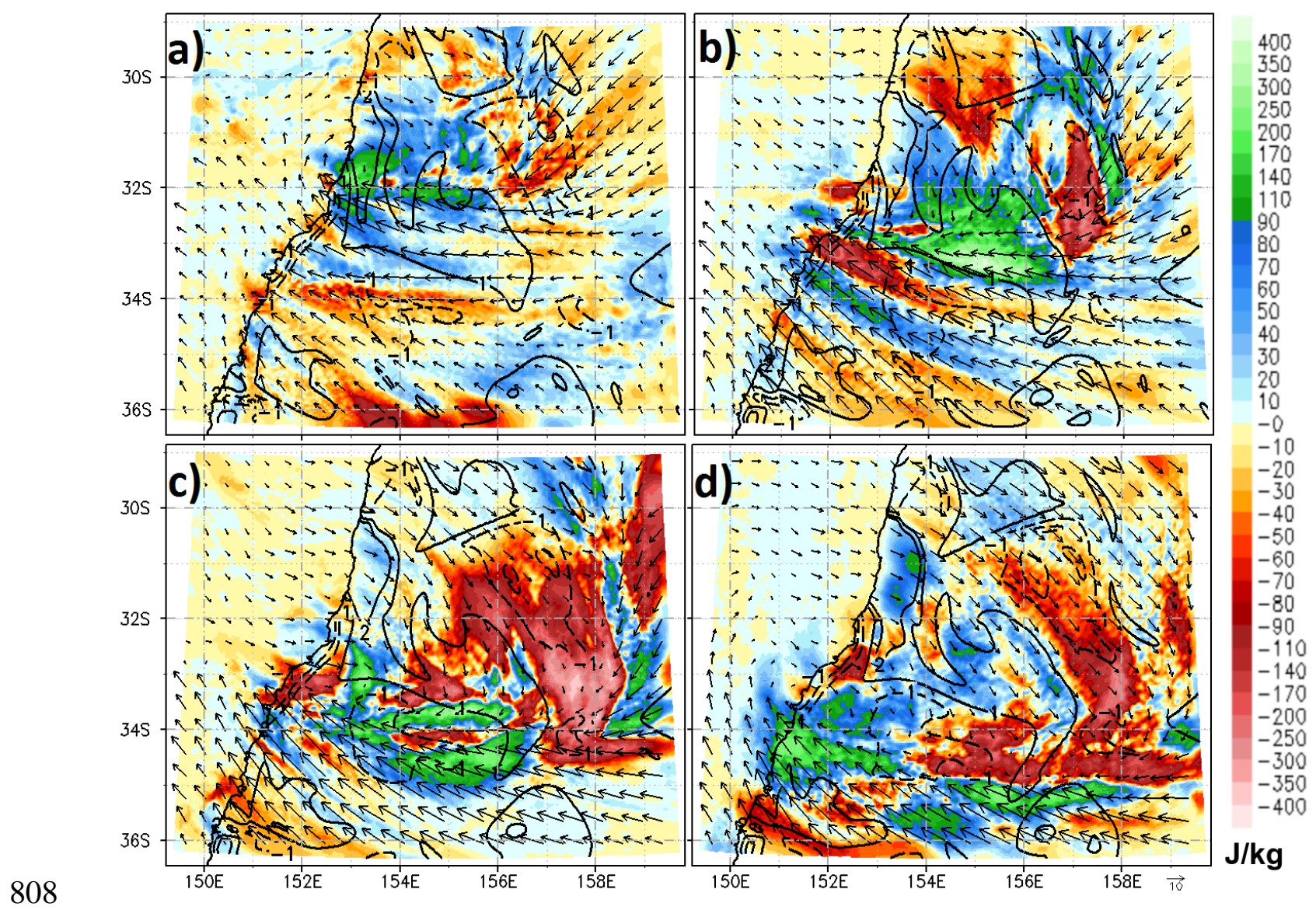

Figure 9: 12-hourly averaged MCAPE differences (JUN07a_BRAN - JUN07a_skin) for a) 0000 to 1200 UTC 7 June, b) 1200 UTC 7 June to 0000 UTC 8 June, c) 0000 UTC to 1200 UTC 8 June, and d) 1200 UTC 8 June to 0000 UTC 9 June. Corresponding 12-hour averaged SST difference (solid black contours for +1 and $+2{ }^{\circ} \mathrm{C}$ and dashed for -1 and $-2{ }^{\circ} \mathrm{C}$ ) and JUN07a_BRAN 10 metre wind vectors are overlayed as where dashed contours indicate negative SST difference. 

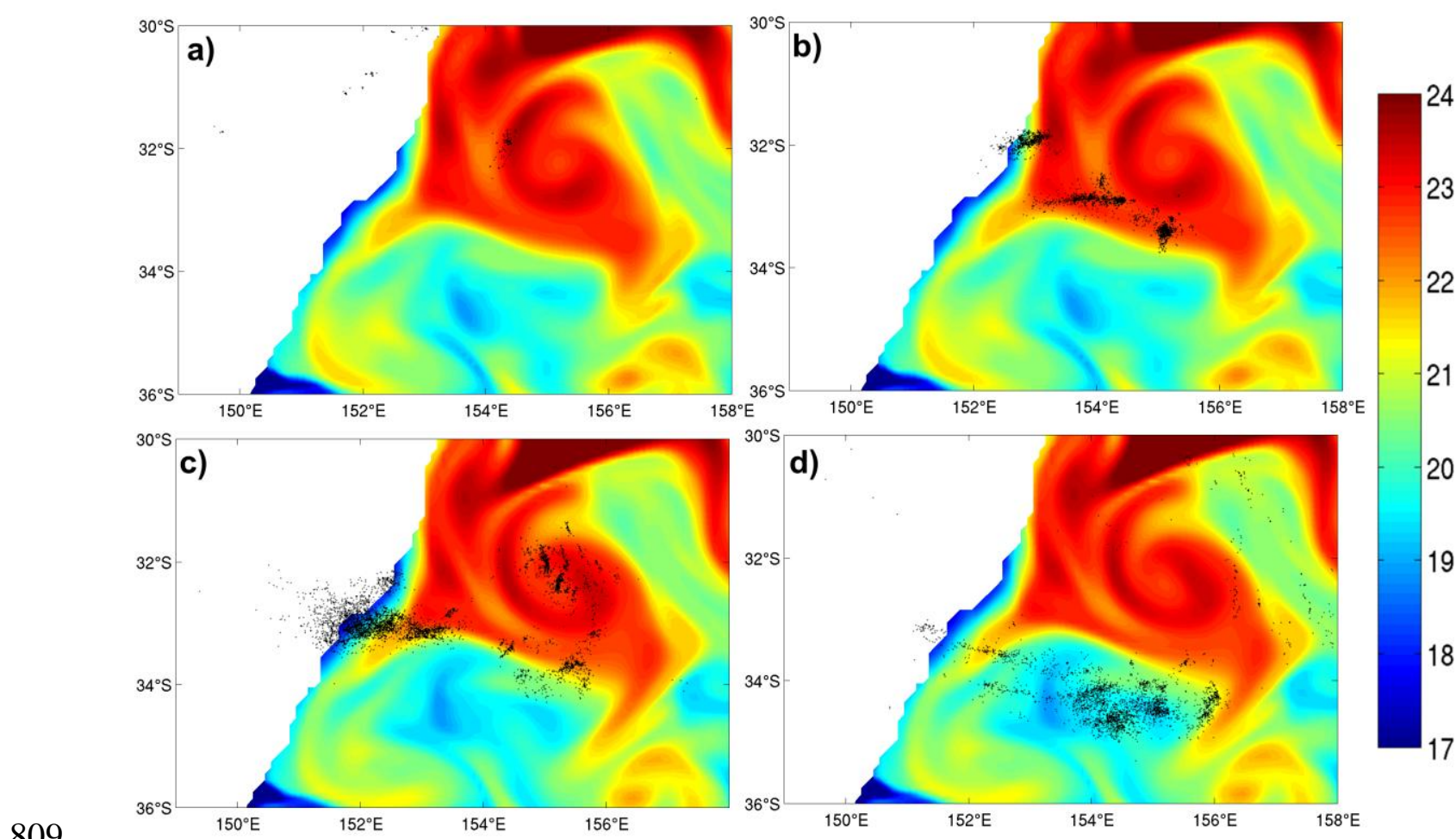

Figure 10: 12-hourly GPATS lightning overlaid on BRAN SST $\left({ }^{\circ} \mathrm{C}\right.$, at start time of each period) for a) 0000 to 1200 UTC 7 June, b) 1200 UTC 7 June to 0000 UTC 8 June, c) 0000 UTC to 1200 UTC 8 June, and d) 1200 UTC 8 June to 0000 UTC 9 June. 


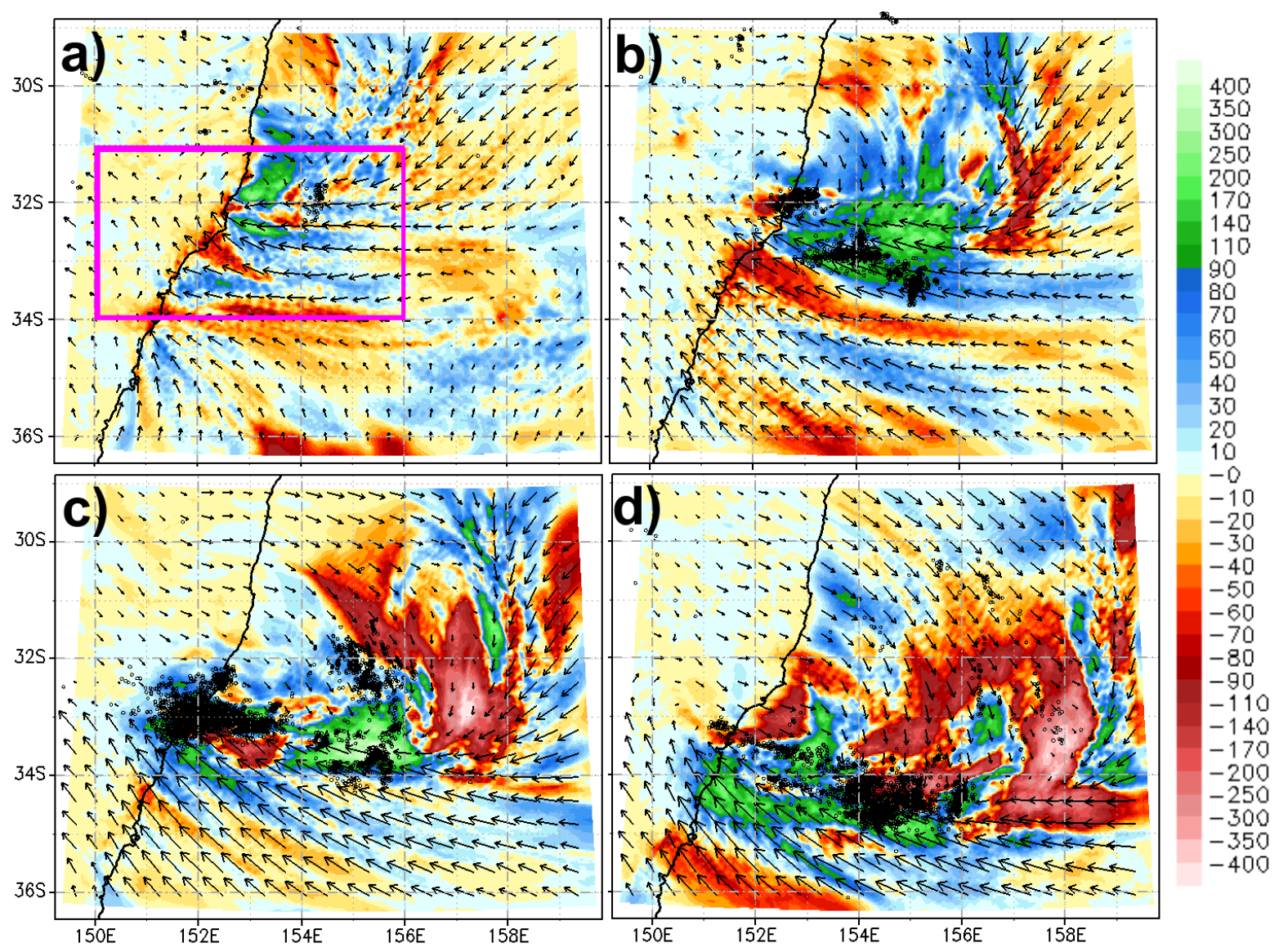

Figure 11: 12-hourly MCAPE difference and winds as in Figure 9 but for 6 hours earlier,

plotted to account for the 6 hour lead seen in the model over the observed, rainfall. Overlaid as black dots are the lightning strikes for the original 12-hour periods as defined in Figure 10. The pink box outlines the zoomed region in Figure 12. 

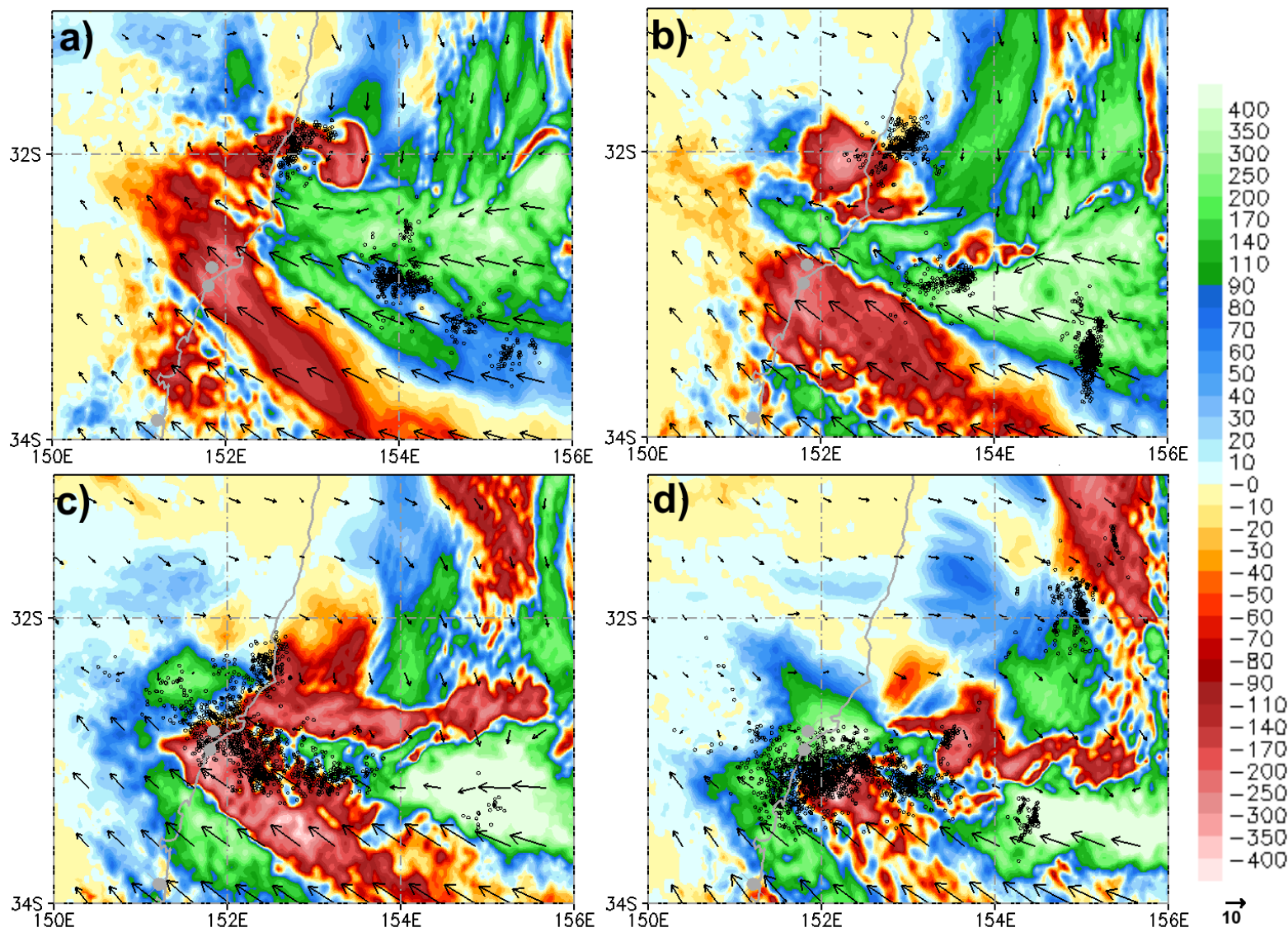

Figure 12: 3-hourly average MCAPE difference $\left(\mathrm{J} \mathrm{kg}^{-1}\right.$, colour shades, JUN07a_BN JUN07a_skin) and 10 metre JUN07a_BN horizontal wind vectors $\left(\mathrm{ms}^{-1}\right.$, representative vector in bottom right) for a) 1200 to 1500 UTC 7 June, b) 1500 to 1800 UTC, c) 1800 to 2100 UTC 7 June, and d) 2100 UTC 7 June to 0000 UTC 8 June. 3 hour total lightning strikes are overlaid for periods 6 hours later than the MCAPE difference plot so the lightning periods are a) 1800 to 2100 UTC 7 June, b) 2100 UTC 7 June to 0000 UTC 8 June, c) 0000 to 0300 UTC, and d) 0300 to 0600 UTC 8 June. In a) are the locations of representative observation station Williamtown, Nobbys, and Sydney. 


\section{University Library}

\section{- M M N E R VA A gateway to Melbourne's research publications}

Minerva Access is the Institutional Repository of The University of Melbourne

Author/s:

Chambers, CRS;Brassington, GB;Walsh, K;Simmonds, I

Title:

Sensitivity of the distribution of thunderstorms to sea surface temperatures in four Australian east coast lows

Date:

2015-10-01

Citation:

Chambers, C. R. S., Brassington, G. B., Walsh, K. \& Simmonds, I. (2015). Sensitivity of the distribution of thunderstorms to sea surface temperatures in four Australian east coast lows. METEOROLOGY AND ATMOSPHERIC PHYSICS, 127 (5), pp.499-517. https:// doi.org/10.1007/s00703-015-0382-4.

Persistent Link:

http://hdl.handle.net/11343/282722 